\title{
Characterization of energy flux partitioning in urban environments: links with surface seasonal properties
}

Article

Published Version

Loridan, T. and Grimmond, C. S. B. (2012) Characterization of energy flux partitioning in urban environments: links with surface seasonal properties. Journal of Applied Meteorology and Climatology, 51 (2). pp. 219-241. ISSN 1558-8432 doi: https://doi.org/10.1175/JAMC-D-11-038.1 Available at https://centaur.reading.ac.uk/33533/

It is advisable to refer to the publisher's version if you intend to cite from the work. See Guidance on citing.

To link to this article DOI: http://dx.doi.org/10.1175/JAMC-D-11-038.1

Publisher: American Meteorological Society

All outputs in CentAUR are protected by Intellectual Property Rights law, including copyright law. Copyright and IPR is retained by the creators or other copyright holders. Terms and conditions for use of this material are defined in the End User Agreement.

www.reading.ac.uk/centaur 
Central Archive at the University of Reading

Reading's research outputs online 


\title{
Characterization of Energy Flux Partitioning in Urban Environments: Links with Surface Seasonal Properties
}

\author{
THOMAS LORIDAN AND C. S. B. GRIMMOND \\ Environmental Monitoring and Modelling Group, Department of Geography, King's College London, \\ London, United Kingdom
}

(Manuscript received 11 February 2011, in final form 12 August 2011)

\begin{abstract}
A better understanding of links between the properties of the urban environment and the exchange to the atmosphere is central to a wide range of applications. The numerous measurements of surface energy balance data in urban areas enable intercomparison of observed fluxes from distinct environments. This study analyzes a large database in two new ways. First, instead of normalizing fluxes using net all-wave radiation only the incoming radiative fluxes are used, to remove the surface attributes from the denominator. Second, because data are now available year-round, indices are developed to characterize the fraction of the surface (built; vegetation) actively engaged in energy exchanges. These account for shading patterns within city streets and seasonal changes in vegetation phenology; their impact on the partitioning of the incoming radiation is analyzed. Data from 19 sites in North America, Europe, Africa, and Asia (including 6-yr-long observation campaigns) are used to derive generalized surface-flux relations. The midday-period outgoing radiative fraction decreases with an increasing total active surface index, the stored energy fraction increases with an active built index, and the latent heat fraction increases with an active vegetated index. Parameterizations of these energy exchange ratios as a function of the surface indices [i.e., the Flux Ratio-Active Index Surface Exchange (FRAISE) scheme] are developed. These are used to define four urban zones that characterize energy partitioning on the basis of their active surface indices. An independent evaluation of FRAISE, using three additional sites from the Basel Urban Boundary Layer Experiment (BUBBLE), yields accurate predictions of the midday flux partitioning at each location.
\end{abstract}

\section{Introduction}

With an ever-increasing portion of the world's population living in cities, interest in the impact of built environments on the local (and global) climate is rising (Grossman-Clarke et al. 2010; McCarthy et al. 2010). A better understanding of local-scale interactions between typical urban units and the atmosphere is needed for both planning-landscaping and climate mitigation strategies (Oleson et al. 2010; Yaghoobian et al. 2010). In particular the key characteristics governing energy exchange between the surface and atmosphere have to be identified if adequate action is to be taken to improve thermal comfort, reduce energy use, or reduce the impacts of extreme heat/cold events. Such knowledge is also critical

Corresponding author address: Thomas Loridan, Environmental Monitoring and Modelling Group, Dept. of Geography, King's College London, London WC2R 2LS, United Kingdom.

E-mail: thomas.loridan@gmail.com for a better characterization of boundary layer processes and therefore for applications in the fields of air quality and pollutant dispersion (Cimorelli et al. 2005; Pérez et al. 2006; Soret et al. 2011).

Since the pioneering work of Oke (1978), who defined a suitable framework for the study of surface-atmosphere energy exchange in urban environments, efforts have been made to collect field observations of surface heat fluxes and to analyze them in a systematic manner (Grimmond 2006). Incoming and outgoing fluxes of solar $(K \downarrow$ and $K \uparrow)$ and longwave $(L \downarrow$ and $L \uparrow)$ radiation, and/or their net components, the net all-wave radiative flux $\left[Q^{*}=(K \downarrow-K \uparrow)+(L \downarrow-L \uparrow)\right]$, are measured directly to determine the input of energy to the surface. Measurements of the turbulent sensible heat $\left(Q_{H}\right)$ and latent heat $\left(Q_{E}\right)$ fluxes provide some insights into how the surface most efficiently dissipates this energy back to the atmosphere. Collectively, these measurements provide valuable information on the surface energy balance (SEB) of typical urban environments (see reviews by 
Oke 1988; Arnfield 2003; Kanda et al. 2002; Christen and Vogt 2004; Offerle et al. 2007; and all references in Table 1). The surface energy balance for an urban area is defined as

$$
Q^{*}+Q_{F}=Q_{H}+Q_{E}+Q_{S}+Q_{A}\left(\mathrm{~W} \mathrm{~m}^{-2}\right)
$$

where $Q_{F}$ refers to the anthropogenic heat contribution, $\Delta Q_{S}$ is the net energy stored in the urban system, and $\Delta Q_{A}$ is the net heat advection. These three fluxes are extremely difficult to measure directly; consequently, they are often estimated indirectly $\left(Q_{F}\right.$ and $\left.\Delta Q_{S}\right)$ (see Offerle et al. 2006; Pigeon et al. 2007; Sailor 2011) or neglected $\left(\Delta Q_{A}\right.$ and $\left.Q_{F}\right)$.

Identifying which surface characteristics of the measurement footprint (or source area) have the strongest impact on surface energy exchanges remains one of the main challenges in the analysis of SEB data. The comprehensive study of Grimmond and Oke (2002), using their multicity urban hydrological database (MUHD), was largely for summertime observations in 10 North American urban sites. They identified relations between the fraction of the plan area vegetated and energy balance flux ratios such as the Bowen ratio (i.e., $Q_{H} / Q_{E}$; see their Fig. 5). Results from Christen and Vogt (2004) using seven sites (three of which were urban) within and around Basel, Switzerland, confirmed these relations. The symbols in Fig. 1, which are in the same form as in Grimmond and Oke (2002), show this relation using 19 datasets (Table 1). This includes observations that are now available for all seasons at some sites. For consistency these data are analyzed in 2-month periods (see numbers in Fig. 1) but the locally weighted scatterplot smoothing (LOWESS) regression (Cleveland 1981) curve uses only short-term and summer periods from sites with annual data (i.e., the regression only uses symbols; Fig. 1). The strong link between the fraction of the surface that is vegetated and the mean daytime ( $\pm 3 \mathrm{~h}$ around solar noon) Bowen ratio is seen clearly. These types of generalized relations help to identify the key processes governing the partitioning of energy at the urban surface, but they also provide some guidance as to what sort of flux values should be expected for a particular area where surface characteristics are known. They have great potential for providing rule-of-thumb values for urban planning and the evaluation of climate mitigation and adaptation strategies; they can therefore serve as simple tools to assess, for instance, the impacts of landscape modifications.

However, the variability identified between points characterizing the same site over a year (i.e., numbers in Fig. 1) suggests that seasonality plays a significant role in the partitioning of energy between the turbulent heat fluxes.
Consequently, the characterization of the surface should account for seasonal variations. Another important factor influencing generalized surface-flux analysis is the contrast in the amount of incoming energy received at each location by time of year. A high-latitude site in winter, for example, will receive hardly any incoming energy (apart from anthropogenic) and would therefore be expected to generate heat fluxes that are considerably different from a similar site at lower latitudes. This too suggests that a site cannot be characterized statically for different times of the year.

The objective of this paper is to address both of these issues. First, consideration is given to normalizing the surface energy balance to account for variations in the amount of energy received at the surface (section 2). A new approach is suggested that uses the incoming radiative fluxes only. It is applied to the analysis of energy fluxes from an extended MUHD dataset, with six sites that have records for over an entire year (Table 1). The geographical range is enhanced, with site locations in Europe (3), Africa (1), Asia (1), and Australia (1) added to the North American (11) sites. Second, a methodology is proposed for characterizing a site (section 3). This newly developed set of site characteristics, the "active surface indices," accounts for seasonal variability. In section 4 the Table 1 database is further analyzed, focusing on the relation between the normalized energy fluxes and the portion of active surface. The database allows the applicability of surface-flux relations to be tested over a wider range of latitudes and seasons, highlighting the impacts of solar exposure (i.e., amount of incoming shortwave radiation) and seasonal changes in surface characteristics. General rule-of-thumb predictive relations are identified, providing the basis for the Flux Ratio-Active Index Surface Exchange (FRAISE) scheme that estimates mean midday $( \pm 3 \mathrm{~h}$ around solar noon) flux ratio values. In section 5 results are used to derive a classification of urban environments suitable for application in, for instance, land surface schemes of atmospheric models. Section 6 presents an independent evaluation of both the site classification system and the FRAISE prediction scheme with the Basel Urban Boundary Layer Experiment (BUBBLE) data.

\section{The normalized surface energy balance}

\section{a. Method}

Direct energy input to the urban surface occurs via the incoming solar $(K \downarrow)$ and longwave $(L \downarrow)$ radiation components. If the net contribution of advection is neglected from (1), this energy, along with a site-dependent anthropogenic $\left(Q_{F}\right)$ contribution, are then partitioned into the outgoing solar $(K \uparrow)$, longwave $(L \uparrow)$, turbulent 

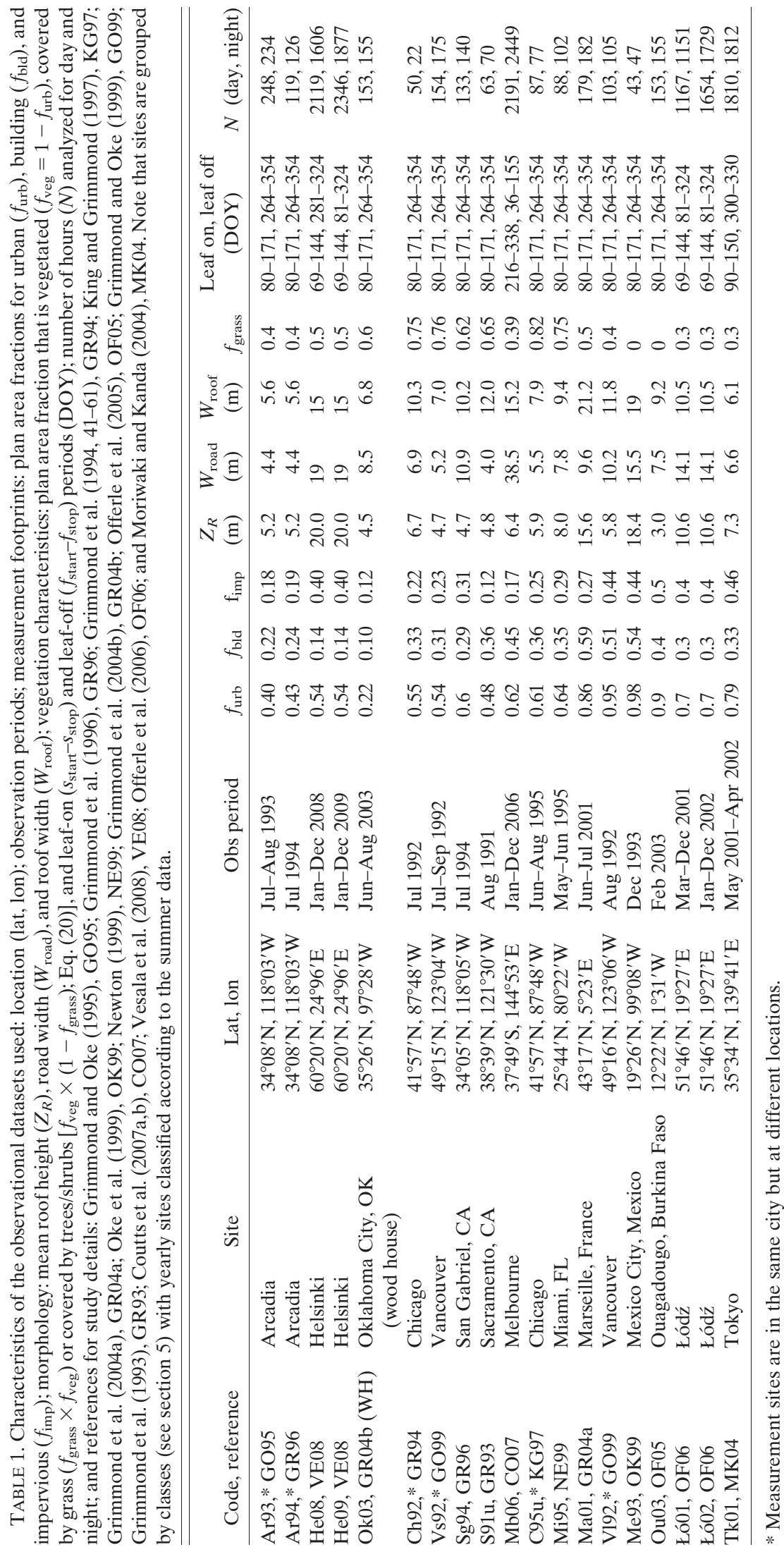


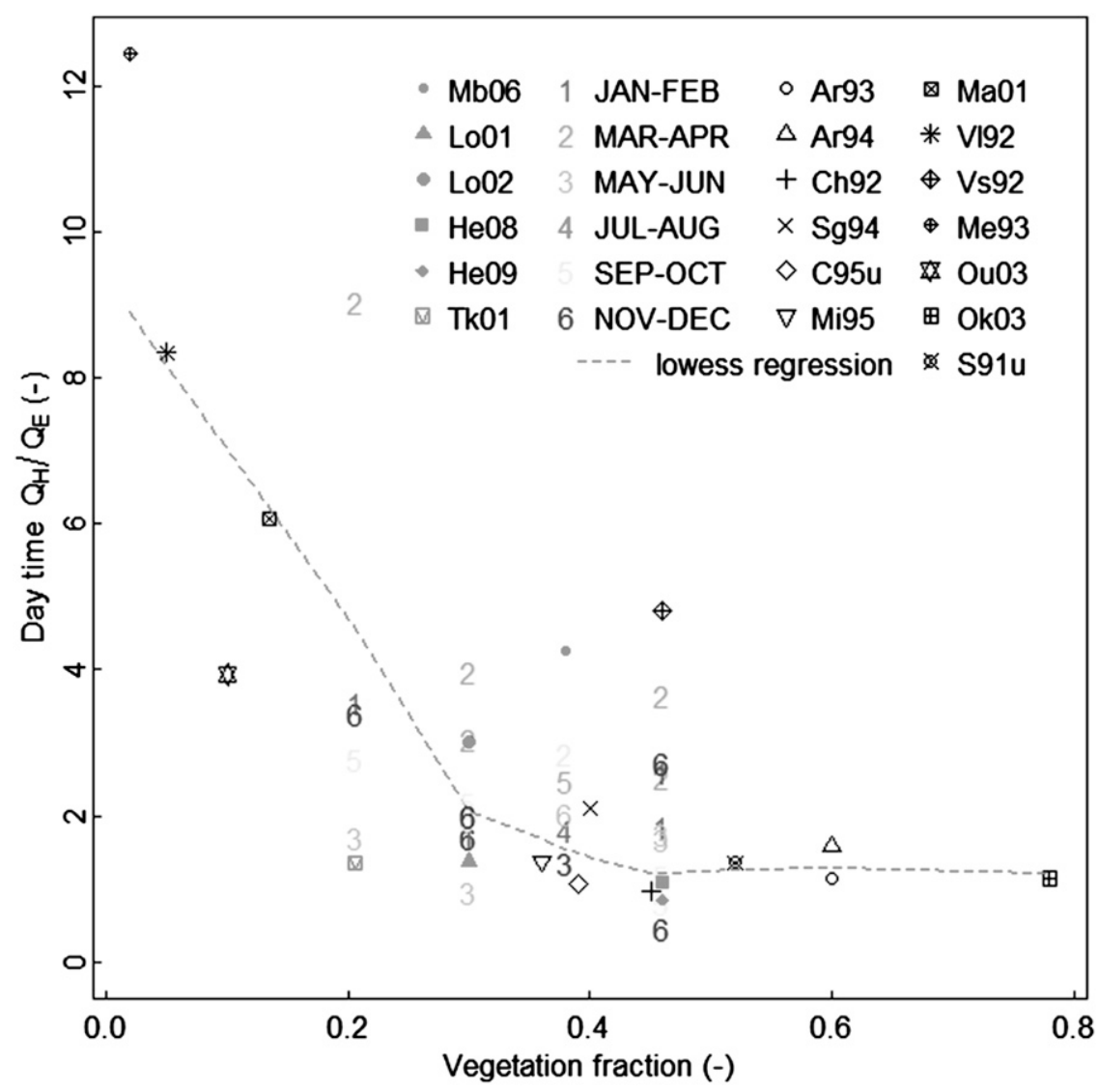

FIG. 1. Mean midday ( $\pm 3 \mathrm{~h}$ around solar noon) Bowen ratio $\left(Q_{H} / Q_{E}\right)$ as a function of vegetation fraction. LOWESS (dashed line) regression performed using summer months and short-term datasets only (i.e., only symbols). See Table 1 for site codes. The fluxes have had the $Q_{F}$ contribution accounted for (see section 2). Note that the shading scheme for numbers is reversed for Mb06 (Southern Hemisphere).

sensible $\left(Q_{H}\right)$, latent $\left(Q_{E}\right)$, and net storage $\left(\Delta Q_{S}\right)$ heat fluxes. Previous studies typically have normalized SEB fluxes by $Q^{*}$ (e.g., Grimmond and Oke 2002; Christen and Vogt 2004; Moriwaki and Kanda 2004; Newton et al. 2007), yet $Q^{*}$ inevitably includes some information on the surface characteristics (albedo and emissivity). Using the total downward radiation instead $(Q \downarrow$ : incoming solar plus incoming longwave radiation) provides a normalizing method independent of the underlying surface, therefore leading to a more comparable set of flux ratios.

After normalization of Eq. (1) by $Q \downarrow$, and omitting net advection, the following nondimensional balance can be derived:

$$
1+\frac{Q_{F}}{Q \downarrow}=\frac{K \uparrow+L \uparrow}{Q \downarrow}+\frac{Q_{H}}{Q \downarrow}+\frac{Q_{E}}{Q \downarrow}+\frac{\Delta Q_{S}}{Q \downarrow} .
$$

The anthropogenic heat flux, which is typically not quantified at all sites because of the effort required (Sailor 2011), is treated here in an equal manner using the appropriate diurnally varying fluxes for each site from the Large-Scale Urban Consumption of Energy (LUCY) model (Allen et al. 2011), providing mean hourly values for each month of data. LUCY estimates $Q_{F}$ based on 2005 data at 2.5 arc $\min \times 2.5$ arc min resolution, but errors are estimated to be less than $20 \mathrm{~W} \mathrm{~m}^{-2}$ and the resultant data will be consistent across all sites. The measured $Q_{H}$ and $L \uparrow$ (or $Q^{*}$ directly) fluxes are then adjusted in the following manner:

$$
\begin{aligned}
Q_{H} & =Q_{H}^{m}-\gamma Q_{F} ; \quad L \uparrow=L \uparrow^{m}-v Q_{F} ; \\
Q^{*} & =Q^{*, m}+v Q_{F},
\end{aligned}
$$

where the superscript $m$ refers to the directly measured values of the fluxes [i.e., as presented in Eq. (2)], $\gamma=0.2$, and $\nu=0.6$, for this study. These ensure that $60 \%$ of the LUCY $Q_{F}$ estimate is accounted for when correcting for the overestimation of $L \uparrow^{m}$ (underestimation of $Q^{*, m}$ ) by radiometers (Grimmond 1992, her appendix 2; Sailor 2011) while the overestimation from the eddy 
covariance system is approximated as $0.2 Q_{F}$. Next, $\Delta Q_{S}$ is derived as a residual of the (adjusted) energy balance. This is equivalent to assuming

$$
\Delta Q_{S}=\Delta Q_{S}^{m}-(1-\gamma-v) Q_{F},
$$

where $\Delta Q_{S}^{m}$ represents the residual of the original (unadjusted) SEB. Note that this methodology does not consider the impacts of anthropogenic moisture on $Q_{E}$ but this should be minimal in the analysis here as no sites (Table 1) contain cooling towers within their measurement footprints. Given Eqs. (3) and (4), Eq. (2) can be written as

$$
\frac{Q \uparrow}{Q \downarrow}+\frac{Q_{H}}{Q \downarrow}+\frac{Q_{E}}{Q \downarrow}+\frac{\Delta Q_{S}}{Q \downarrow}=1 .
$$

From estimation of each of the fluxes in Eq. (5), urban environments can be characterized in terms of how they partition incoming energy. This characterization is independent of the amount of energy received and is not based on information about the surface other than the relative importance of the outgoing fluxes generated.

\section{b. Site database}

To illustrate the contrasting patterns of behavior of different urban environments, the database (Table 1) is analyzed in terms of the flux ratios presented in Eq. (5). For all sites the turbulent sensible and latent heat fluxes were obtained using the eddy covariance technique, and $Q^{*}$ was obtained from radiation measurements (see individual study details; Table 1). In most cases the four components of the radiation budget $(K \downarrow, L \downarrow, K \uparrow$, and $L \uparrow$ ) were measured, but for some of the older measurements campaigns the longwave components are missing (as $Q^{*}$ was observed directly with net radiometers). In such situations, the $L \downarrow$ flux needed to normalize all fluxes in Eq. (5) is modeled using the methodology from Loridan et al. (2011).

Most observation periods lasted between 4 and 8 weeks (hereinafter called short-term datasets), except for the Melbourne, Victoria, Australia (Mb06), and Tokyo, Japan (Tk01), datasets, which cover an entire year, and the Helsinki, Finland (He08, He09), and Łódź, Poland (Łó01, Łó02), campaigns, which spanned over two years ("long term" datasets). All short-term datasets were collected close to the time of maximum solar receipt (late spring-early summer) except Me93 (December) and Ou03 (February). To study seasonal variability, longer datasets are analyzed in 2-month periods.

Figure 2 shows the mean diurnal evolution of the normalized fluxes introduced in Eq. (5) for four of the shortterm campaigns (Ok03, $\mathrm{Sg} 94, \mathrm{Ma} 01$, and $\mathrm{Ou} 03$; Table 1$)$. The midday ( $\pm 3 \mathrm{~h}$ around solar noon) values of the flux ratios provide an indication of the most efficient energy transfer from the surface to the atmosphere. Clear differences are evident between sites: for the most vegetated site (Ok03; Fig. 2a), energy is efficiently dissipated via evaporative processes $(15 \%-20 \%$ of $Q \downarrow)$, and although a strong time dependency of the day time energy release is observed, the relative importance of the midday $Q_{H}$, $Q_{E}$, and $\Delta Q_{S}$ fluxes is comparable. As the sites become more urbanized, the $Q_{E}$ contribution is reduced [ $\sim 10 \%$ of $Q \downarrow$ for $\mathrm{Sg} 94$ (Fig. 2b) and $\sim 5 \%$ for $\mathrm{Ma} 01$ and $\mathrm{Ou} 03$ (Figs. 2c,d)]; energy is dissipated mainly via radiative processes or turbulent sensible heat or is stored. For Ma01 (Fig. 2c), the loss of energy via turbulent sensible heat is $\sim 30 \%$ of $Q \downarrow$ and considerably exceeds both the daytime storage and latent heat fluxes; for $\mathrm{Ou} 03$ the dominant daytime contribution is from storage ( $\sim 20 \%$ of $Q \downarrow$; Fig. 2d). For $\mathrm{Sg} 94$ both processes are of similar magnitude at midday, with $\Delta Q_{S}$ dominant in the morning and $Q_{H}$ in the afternoon.

During the night, the amount of outgoing radiation exceeds the incoming value and the $Q \uparrow(=K \uparrow+L \uparrow)$ ratio is greater than one ( $K \uparrow=K \downarrow=0$ and more energy is emitted as $L \uparrow$ than is received as $L \downarrow)$. The storage ratios are negative, indicating heat release from the urban fabric. Although both phenomena occur for all four sites, the magnitudes of the two normalized fluxes vary significantly. For the most extreme cases of Ma01, up to $40 \%$ of $L \downarrow$ is released from storage, while close to $130 \%$ is emitted as $L \uparrow$. Nighttime turbulent fluxes are small but an important distinction can be made with regard to the sign of $Q_{H}$. It remains positive in Ma01 (energy lost by the surface), turns negative in Ok03 (energy gained by the surface), and is close to 0 at the other two sites. These results have particular importance for the estimation of mixing layer heights in, for instance, applications linked to air quality.

The daytime ( $\pm 3 \mathrm{~h}$ around solar noon) and night time ( $\pm 3 \mathrm{~h}$ around $12 \mathrm{~h}$ after solar noon) flux ratios (Table 2) allow the contribution of each flux to the midday (peak) energy loss from the surface to be compared with the low nighttime energy input. The sites with short-term data (Table 2a) are ordered by their mean midday $\left(Q_{H}+\right.$ $\left.Q_{E}\right)$ ratio values, which highlight the energy trade-off occurring between the turbulent fluxes and the radiative-storage ones. For sites with strong turbulent activity (e.g., Ma01, where $Q_{H}=0.28 Q \downarrow$ is the highest; or the Chicago, Illinois, datasets, where $\left.Q_{E}>0.16 Q \downarrow\right)$ ), the $Q \uparrow$ contribution is at its minimum $(\sim 0.53 Q \downarrow)$ and the storage is limited $(\sim 0.15 Q \downarrow)$. For sites like Me93 and Ou03, where turbulent heat exchange is weak $\left(Q_{E}<\right.$ $\left.0.04 Q \downarrow ; Q_{H}<0.14 Q \downarrow\right)$, both longwave emissions $(Q \uparrow \sim$ $0.65 Q \downarrow)$ and storage $\left(\Delta Q_{S}=0.225 Q \downarrow\right.$ for Me93 and $\sim 0.17 Q \downarrow$ for $\mathrm{Ou} 03)$ are enhanced. Note that the correction for the $Q_{F}$ contribution [Eqs. (3) and (4)] is 

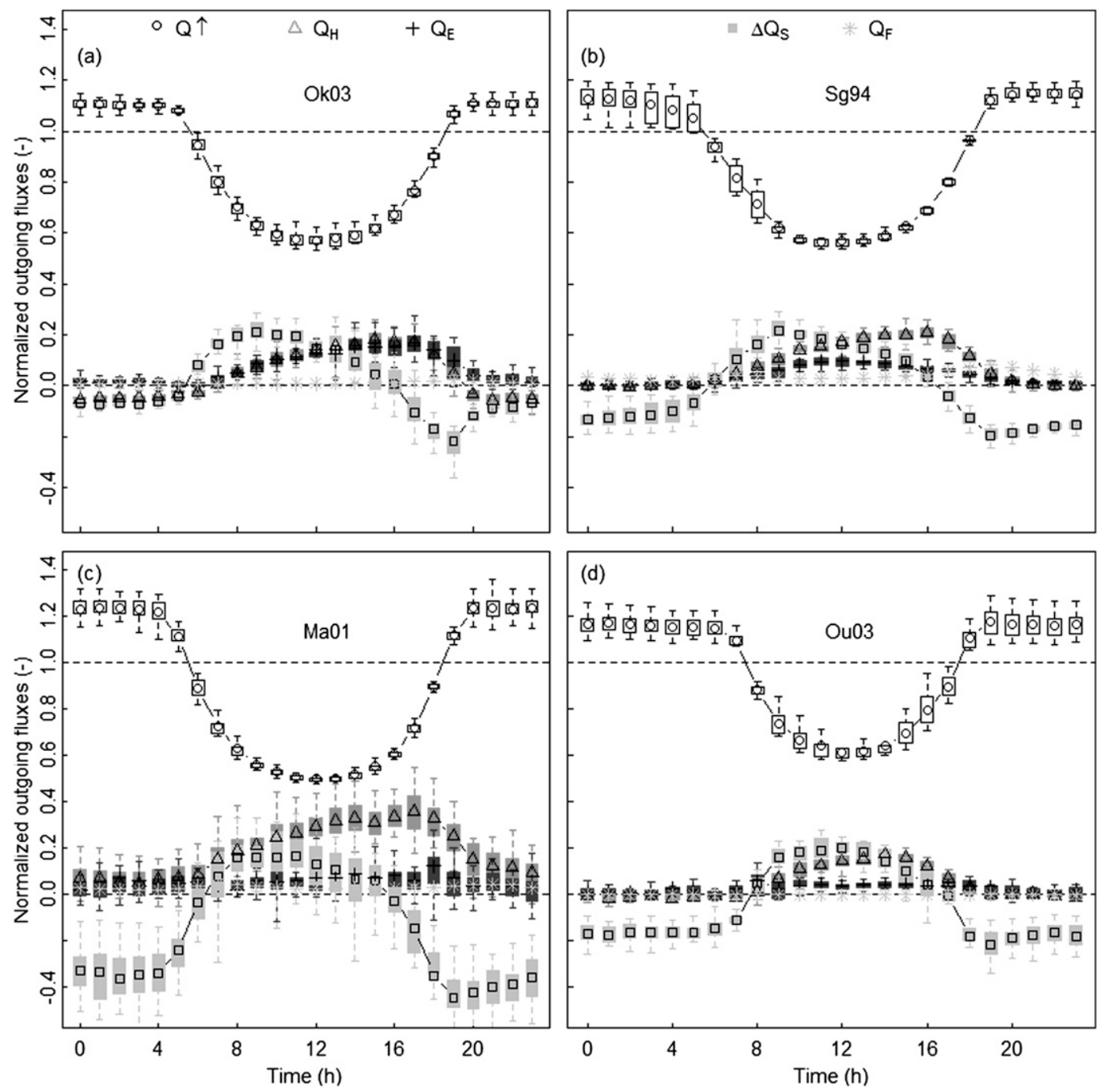

FIG. 2. Mean diurnal flux ratios (symbols) and box plots [showing interquartile range (IQR) and whiskers for values within 1.5 IQR] for (a)-(d) four of the short-term datasets. Positive (negative) values of $Q_{H}, Q_{E}$, and $Q \uparrow$ indicate energy lost (gained) by the surface. The opposite is true for $\Delta Q_{S}$. See Table 1 and text for site codes. Plots are ordered by decreasing mean midday latent heat flux ratio (computed at $\pm 3 \mathrm{~h}$ around solar noon; see Table 2).

accounted for in all fluxes, and ratios consequently add up to 1 [Eq. (5)]. The highest $Q_{F}$ estimates are $\sim 0.08 Q \downarrow$ for the Vancouver, British Columbia, Canada, sites (V192, Vs92).

At night the sign of the $Q_{H}$ ratio is of interest. Only Ma01 and Me93 exhibit a significant positive contribution ( $\sim 0.08 L \downarrow$ for Ma01, $\sim 0.07 L \downarrow$ for Me93), suggesting that nighttime conditions remain unstable at these highly urbanized sites, whereas Ok03 and Chicago (Ch92, C95u) have larger negative contributions more characteristic of stable conditions. The storage heat release is largest for Ma01 and Me93 $(\sim 0.4 L \downarrow)$, as are the $L \uparrow$ contributions $(\sim 1.3 L \downarrow)$. For all other sites, the storage heat release hardly accounts for $(0.1-0.2) L \downarrow$ and $L \uparrow$ is $<1.2 L \downarrow$.

Long-term datasets are analyzed in 2-month periods (Tables 2b-e). For seasonal consistency, Mb06 is shown offset by 6 months. The periods with large $Q \downarrow$ are shown in boldface for each site to enable a direct comparison with Table 2a sites. In spring, Łódź, Helsinki, and Melbourne behave in a more similar way than the Arcadia, California, or Chicago sites with a $\left(Q_{H}+Q_{E}\right)$ ratio $(0.28-0.32) Q \downarrow$. Water restriction in Melbourne (Melbourne Water 2010) causes the vegetation to be increasingly stressed toward the end of the summer and autumn (Table 2d). Tk01 in the summer would be most comparable to Mi95 with all ratios in the middle of the observed range of values.

The role of seasonality in flux partitioning is most obvious for the high-latitude sites (Łódź and Helsinki; Tables $2 \mathrm{~b}, \mathrm{c})$, notably in the variation of the midday $Q \uparrow$ ratio through the year. Spring and summer seasons have 
a smaller portion of the incoming radiant energy dissipated as $Q \uparrow$ and a higher fraction through the turbulent exchange of moisture (and heat). The period with biggest daytime storage (May-June in both cases) also coincides with the minimum midday $Q \uparrow$ ratio. In winter, the $Q \uparrow$ ratio reaches its maximum [(0.8-0.9) $Q \downarrow]$ with the other ratios below $0.1 Q \downarrow$. Note that the $\Delta Q_{S}$ contribution remains negative during the day, suggesting that the surface is still releasing heat at peak daytime exposure. Potential errors in the $Q_{F}$ estimate from LUCY are assumed to be less than $0.01 Q \downarrow$ for these sites in the winter.

For lower-latitude sites (Melbourne and Tokyo; Tables $2 \mathrm{~d}, \mathrm{e}$ ), the seasonality in flux ratios is not as pronounced; yet the evolution of the $Q_{E}$ and $Q_{H}$ ratios is in agreement with Tables $2 \mathrm{~b}$,c. Changes in the $\Delta Q_{S}$ (and $Q \uparrow$ ) ratios are limited with no clear seasonal pattern. Moriwaki and Kanda (2004) made a similar conclusion in their study of their Tk01 dataset in which they argue that the winter storage is unexpectedly large relative to "earlier models of storage heat" (Moriwaki and Kanda 2004, p. 1704). They point out that although the observed $K \downarrow$ values are much larger in the summer than in winter, this is not the case of the normal incident component (larger in the winter) and they suspect that this leads to an energy input "as strong as that in the summer locally on an urban facet that is normally directed to the sunshine" (Moriwaki and Kanda 2004, p. 1704). Finally, they conclude that "this result is probably because the urban canopy has surfaces oriented in all directions and, thus, can readily absorb normal incident radiation even when the sun is at low angles" (Moriwaki and Kanda 2004, p. 1709).

The annual variation in nighttime flux ratios is much weaker than during the daytime. Positive nighttime ratios of $Q_{H}$ occur in the winter months for Helsinki-Łódź and in the summer for Tokyo, while for the rest of the year and for Melbourne they are mostly negative, indicating that the surface is heated during the night via turbulent sensible heat processes. The minimum values are for Helsinki in the summer and Melbourne in the winter $(\sim-0.08 L \downarrow)$. For Tokyo, Helsinki, and Łódź, the maximum heat release from storage occurs in the winterautumn $(\sim 0.2 L \downarrow$ for Helsinki and Łódź and $\sim 0.15 L \downarrow$ for Tokyo) while in Melbourne this occurs in the summer $(\sim 0.24 L \downarrow)$.

This analysis shows that energy partitioning in urban areas varies between sites and by season. To investigate the extent to which seasonal variations in flux ratios are linked to surface properties of a given site, for example whether vegetation is in leaf, or not, the concept of an active surface with regard to energy exchange is presented with the intent of relating flux ratios to (nonstatic) surface properties.

\section{The active surface}

To determine which portion of the overall surface is mainly responsible for the exchange of heat between the urban surface and the atmosphere through the year, a simple model for simulating shading patterns within city streets and changes in leaf areas is presented. We focus on these two processes because of their strong seasonality and direct impact on energy exchange. The model adopts a "tile approach" in which the environment is split between an urban part (buildings and streets) and a vegetated one (parks and gardens). For simplicity this approach does not account for interactions between the two (e.g., trees shading part of the streets).

\section{a. The urban fraction}

The portion of the total urban fabric (roof-road-walls) exposed to direct solar radiation varies considerably depending on site location, time of year, hour of day, and urban geometry-morphology. In the current approach, street geometry is defined by three parameters (Fig. 3a) characterizing the local-scale mean building height $Z_{R}$, mean roof width $W_{\text {roof }}$, and mean road width $W_{\text {road }}$ for an area. For simplicity, buildings are assumed to be square in plan area and cover the entire street length; that is, a generic urban unit (Fig. 3b) is composed of a roof with a surface plan area cover, $W_{\text {roof }}^{2}$, and a street with a plan area cover, $W_{\text {road }} \times W_{\text {roof }}$.

Each is normalized by the total length of the urban tile for the calculations of shading patterns inside the canyon (Kusaka et al. 2001):

$$
\begin{aligned}
& r=\frac{W_{\text {roof }}}{W_{\text {roof }}+W_{\text {road }}} ; \quad w=\frac{W_{\text {road }}}{W_{\text {roof }}+W_{\text {road }}} ; \\
& h=\frac{Z_{R}}{W_{\text {roof }}+W_{\text {road }}} .
\end{aligned}
$$

Consequently, the plan, frontal, and complete area indices often referred to in the literature $\left(\lambda_{P}, \lambda_{F}\right.$, and $\lambda_{C}$; Grimmond and Oke 1999) can be linked to $h$ and $r$ :

$$
\begin{aligned}
& \lambda_{P}=\frac{\left.W_{\text {roof }}^{2}\right)}{\left(W_{\text {roof }}+W_{\text {road }}\right) W_{\text {roof }}}=\frac{W_{\text {roof }}}{W_{\text {roof }}+W_{\text {road }}}=r \\
& \lambda_{F}=\frac{Z_{R} W_{\text {roof }}}{\left(W_{\text {roof }}+W_{\text {road }}\right) W_{\text {roof }}}=\frac{Z_{R}}{W_{\text {roof }}+W_{\text {road }}}=h, \text { and } \\
& \lambda_{C}=\frac{W_{\text {roof }}^{2}+4 W_{\text {roof }} Z_{R}}{\left(W_{\text {roof }}+W_{\text {road }}\right) W_{\text {roof }}}=\frac{W_{\text {roof }}+4 Z_{R}}{W_{\text {roof }}+W_{\text {road }}}=r+4 h
\end{aligned}
$$

A surface is considered active if it is exposed to direct solar radiation. Although this definition is most relevant 


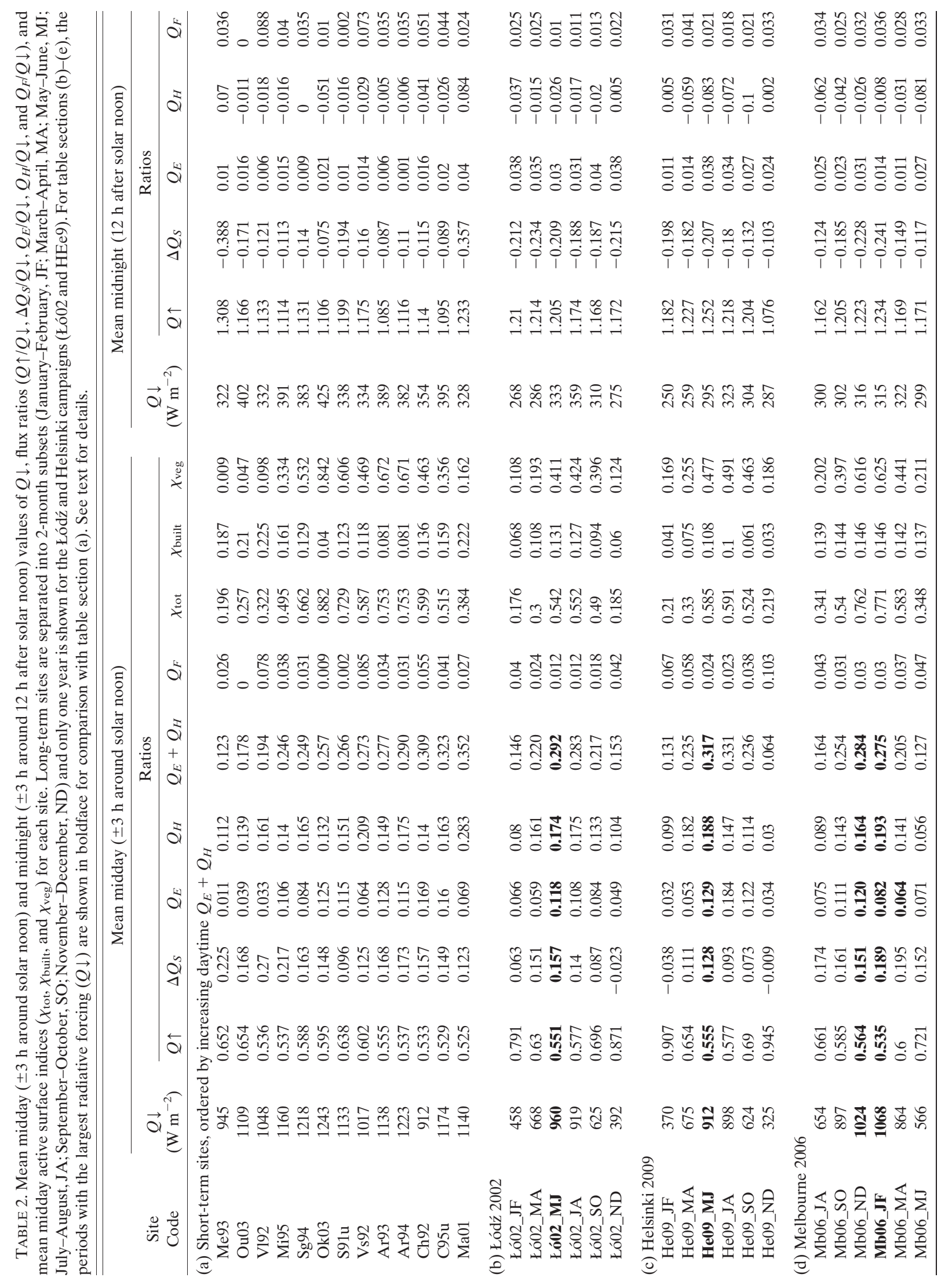




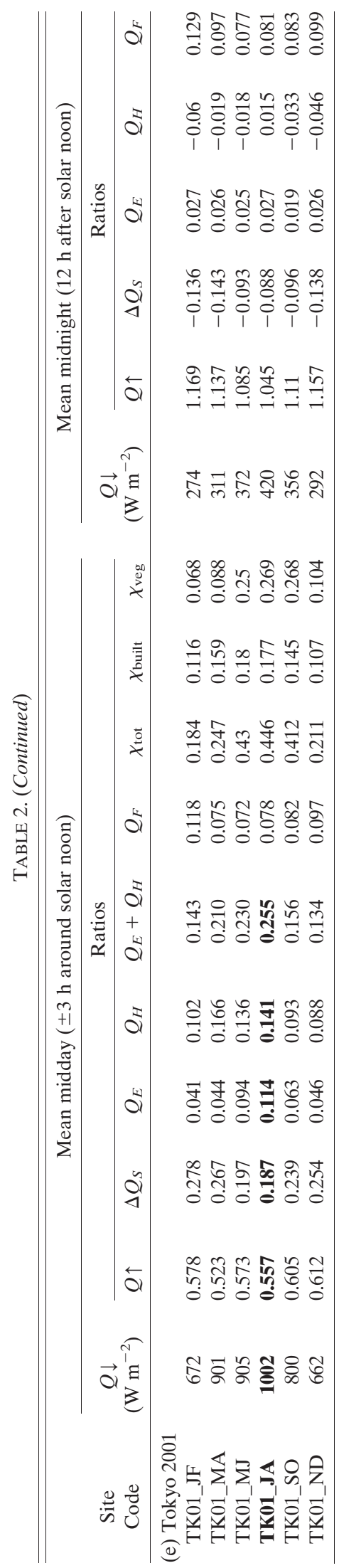

for clear days, it extends to all sky conditions: even on a cloudy day, the active portion of the surface (i.e., that which would have been directly sunlit given clear skies) has a higher potential to have had active heating than the constantly shaded portion. For instance, it is likely to have received radiation during previous clear or partly cloudy sky conditions and to receive a greater amount of $Q \downarrow$ due to the nonisotropic nature of radiation. To ensure a large number of data points (see $N$; Table 1) and to keep a wide scope of application, the concept of an "active surface" will be used under all sky conditions. As more long-term datasets become available, there may be sufficient data to distinguish differences between cloud conditions.

Road surfaces only become active when the sun is high enough above the horizon to illuminate the bottom of the canyon. When the canyon is oriented perpendicular to the solar azimuth angle (i.e., $\theta_{C}=\theta_{S}-\pi / 2$; see Fig. 4a), the critical solar zenith angle $\theta_{\text {Zlim }}$ for which a portion of the road starts to be active is

$$
\theta_{\text {Zlim }}=\tan ^{-1}(w / h)
$$

Figure $4 \mathrm{~b}$ illustrates how the normalized active portion of the road $w_{\text {act }}$ is computed when the solar zenith angle is lower than the critical value $\left(\theta_{Z}<\theta_{Z \text { lim }}\right)$ in this particular case (i.e., $\theta_{C}=\theta_{S}-\pi / 2$ ). All canyon orientations need to be considered. Here, Kusaka et al.'s (2001) approach is adopted: for a given canyon orientation $\theta_{C}$, the normalized portion of the street that is shaded $l_{\text {shadow }}$ is computed as a function of the solar azimuth angle $\theta_{S}$ (Fig. 4a):

$$
\begin{aligned}
l_{\text {shadow }}\left(\theta_{C}\right) & =h \tan \left(\theta_{Z}\right) \sin \left(\theta_{S}-\theta_{C}\right) \quad \text { and } \\
\theta_{Z \lim } & =\tan ^{-1}\left[\frac{w}{h \sin \left(\theta_{S}-\theta_{C}\right)}\right] .
\end{aligned}
$$

Using the latitude of the site $\phi$, solar zenith angle $\theta_{Z}$, declination angle $\delta$, and hour angle $w_{t}$, expressions for shadow length and active portion of the road can be summarized:

$$
\begin{aligned}
& l_{\text {shadow }}\left(\theta_{C}\right) \\
& =h \tan \left(\theta_{Z}\right)\left[\begin{array}{l}
\frac{\cos (\delta) \sin \left(w_{t}\right)}{\cos \left(\theta_{S}\right)} \cos \left(\theta_{C}\right) \\
-\frac{\cos \left(\theta_{Z}\right) \sin (\phi)-\sin (\delta)}{\cos \left(\theta_{S}\right)} \cos (\phi) \sin \left(\theta_{C}\right)
\end{array}\right]
\end{aligned}
$$

and

$$
w_{\text {act }}\left(\theta_{C}\right)=w-l_{\text {shadow }}\left(\theta_{C}\right) .
$$



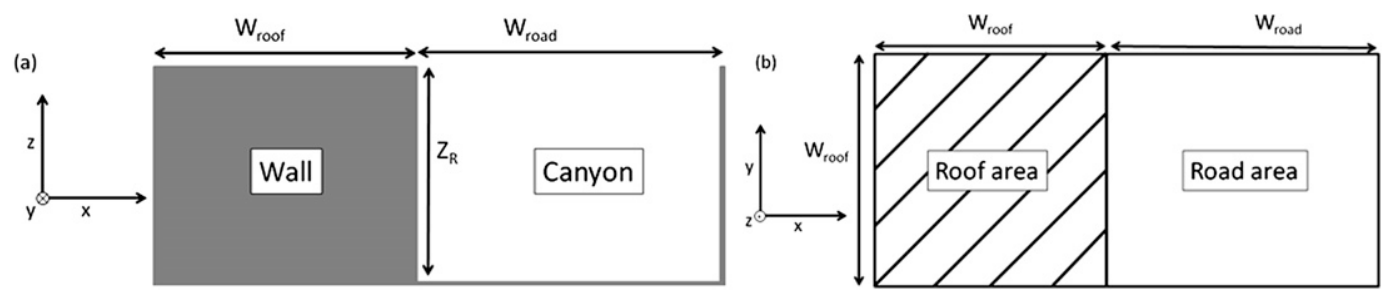

FIG. 3. Geometry of the generic urban unit in the active surface model: (a) vertical (cross section) and (b) plan view.

At any time at least one of the two walls composing the canyon is totally in shadow, while the other can be either fully sunlit $\left(\theta_{Z} \leq \theta_{Z \text { lim }}\right)$, in which case the entire wall is considered active $\left(h_{\text {act }}=h\right)$, or in the shadow $\left(\theta_{Z}<\theta_{\text {Zlim }}\right.$; Fig. $\left.4 \mathrm{c}\right)$. The portion of the active wall is derived from

$$
\begin{aligned}
& h_{\text {act }}\left(\theta_{C}\right) \\
& =\frac{w}{\tan \left(\theta_{Z}\right)}\left[\begin{array}{l}
\frac{\cos (\delta) \sin \left(w_{t}\right)}{\cos \left(\theta_{S}\right)} \cos \left(\theta_{C}\right) \\
-\frac{\cos \left(\theta_{Z}\right) \sin (\phi)-\sin (\delta)}{\cos \left(\theta_{S}\right)} \cos (\phi) \sin \left(\theta_{C}\right)
\end{array}\right] .
\end{aligned}
$$

The criteria for roof surfaces to be active are simpler, since no obstruction from other buildings can occur with the current geometry. The roof is either fully active $\left(r_{\text {act }}=r\right)$, when the sun is able to reach part of the wall (i.e., if $\left.h_{\text {act }}>0\right)$, or fully shadowed $\left(r_{\text {act }}=0\right)$ ). Roof geometry (e.g., pitched roofs) would lead to partial shadowing of the surfaces but this is not accounted for.
Equations (13) and (15) are for canyon orientation $\theta_{C}$. Assuming street orientations are distributed isotropically, and given the symmetry of the canyon geometry, the active portion of the three types of surfaces can be derived as

$$
\begin{aligned}
& w_{\mathrm{act}}=\frac{1}{n} \sum_{i=1}^{n} w_{\mathrm{act}}\left(i \frac{\pi}{n}\right) ; \quad h_{\mathrm{act}}=\frac{1}{n} \sum_{i=1}^{n} h_{\mathrm{act}}\left(i \frac{\pi}{n}\right) ; \\
& r_{\mathrm{act}}=\frac{1}{n} \sum_{i=1}^{n} r_{\mathrm{act}}\left(i \frac{\pi}{n}\right) .
\end{aligned}
$$

The complete urban surface is composed of one roof, four walls (two are shadowed at any time), and one road (Fig. 3b). The active portion of the total urban surface $u_{\text {act }}$ is, therefore,

$$
u_{\mathrm{act}}=r_{\mathrm{act}}+2 h_{\mathrm{act}}+w_{\mathrm{act}} .
$$

Normalizing the four active portions by the corresponding total amount of that facet in the urban tile, active fractions are derived:
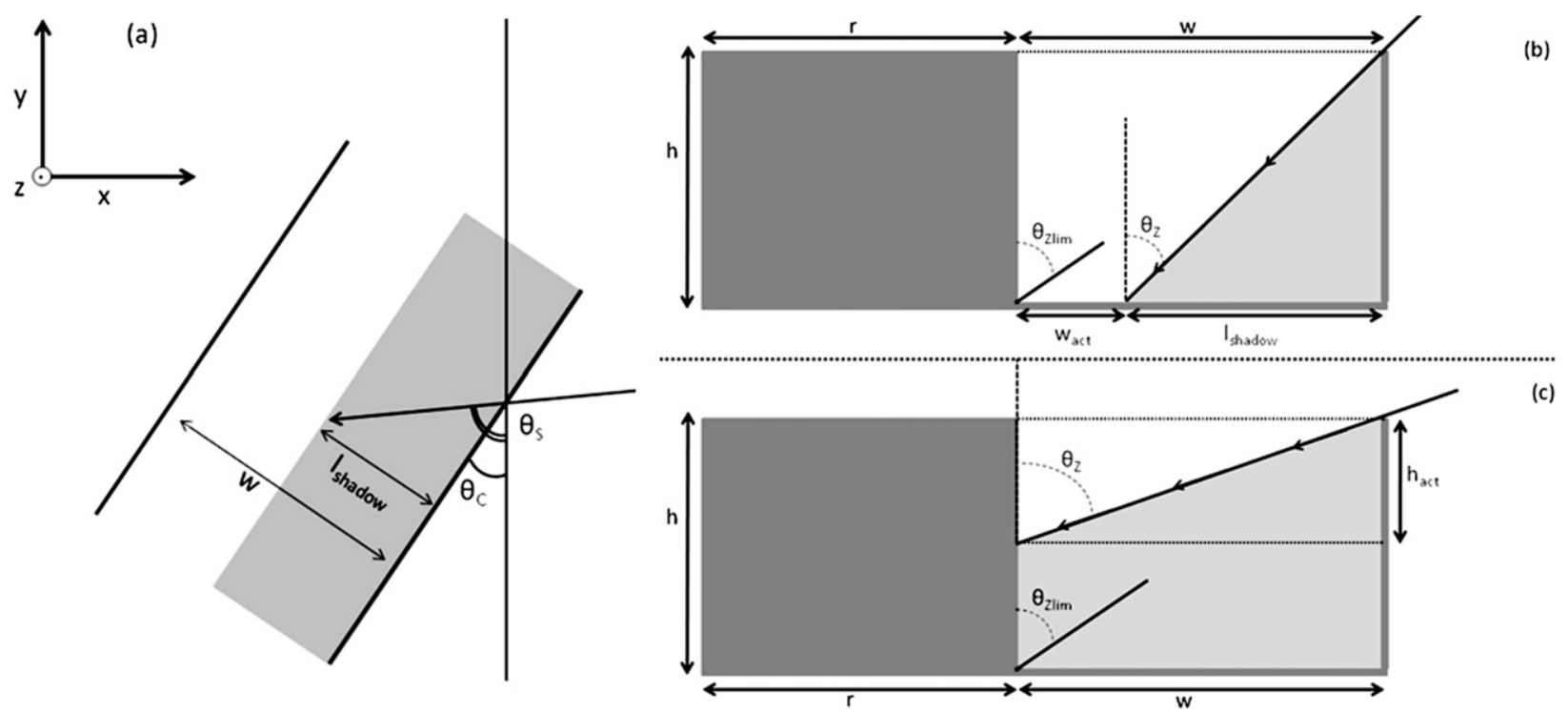

FIG. 4. (a) Impacts of canyon orientation $\theta_{C}$ and solar azimuth angle $\theta_{S}$ on the street-shading patterns (H. Kusaka 2010, personal communication), where $w$ is the normalized mean street width and $l_{\text {shadow }}$ is the normalized portion of the street that is shaded. Also shown are shading patterns (cross sections) for (b) roads and (c) walls. See text for notation. 

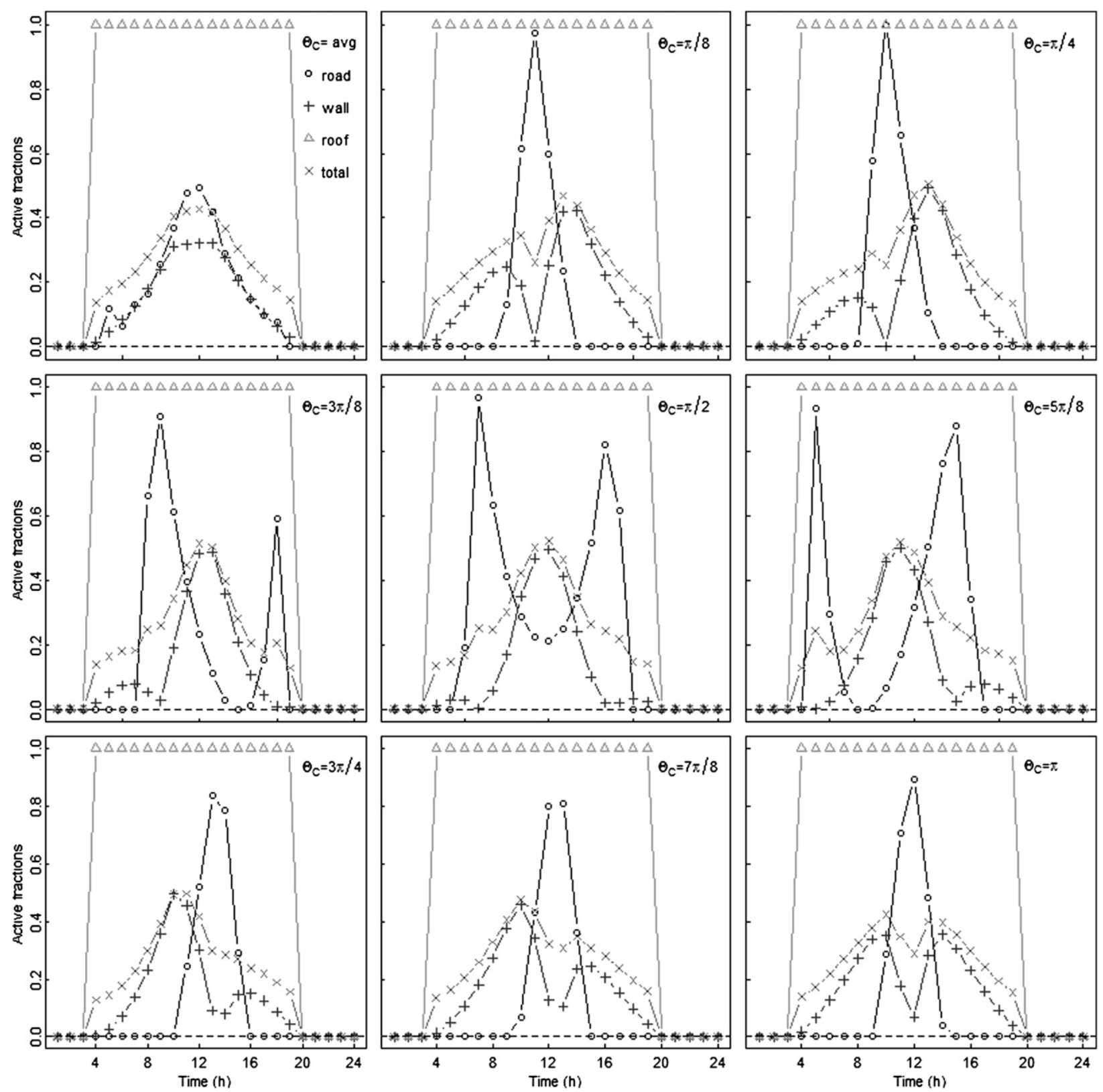

FIG. 5. Fractions of total, roof, road, and wall materials that are active for each hour of DOY 172 in Łódź for different canyon orientations $\left(\pi / 8 \leq \theta_{C} \leq \pi\right)$ and (top left) for the overall average $\left(\theta_{C}=\right.$ avg).

$$
\begin{aligned}
f_{\text {act }, r} & =\frac{r_{\text {act. }}}{r} ; \quad f_{\text {act }, h}=\frac{h_{\text {act }}}{2 h} ; \quad f_{\text {act }, w}=\frac{w_{\text {act }}}{w} ; \\
f_{\text {act }, u} & =\frac{u_{\text {act }}}{r+4 h+w} .
\end{aligned}
$$

The evolution of these fractions for Łódź (Table 1) on 21 June [day of year (DOY) 172] is shown in Fig. 5 for all canyon orientations and the eight individual $\theta_{C}$ values used here (i.e., $n=8$ ). While roof and road surfaces can be fully active $\left(f_{\text {act }, r} \leq 1 ; f_{\text {act }, w} \leq 1\right)$, this cannot be the case for wall surfaces $\left(f_{\text {act }, h} \leq 0.5\right)$ and consequently for the total urban surface. Contrasting shading patterns for the road and wall surface are obvious for all $\theta_{\mathrm{C}}$ orientations: when, for instance, the canyon is perpendicular to the solar azimuth angle $\left(\theta_{C}=\pi / 2\right)$, the active portion of the wall becomes mainly active at noon (directly sunlit) while the road is mostly shaded (wall obstruction). At midday the maximum sun exposure of the road occurs for $\theta_{C}=\pi$, which coincides with a minimum wall exposure (canyon aligned with the solar azimuth angle). 


\section{b. The vegetated fraction}

To consider the impacts of vegetation on flux partitioning, phenology is critical. Here, the vegetated tile is considered to have a fraction grass $\left(f_{\text {grass }}\right.$; Table 1$)$ and the remainder is assumed to be trees/shrubs. For the trees/shrubs, a minimum and maximum leaf area index (LAI; here set to 1 and 6, respectively, i.e., assumed to be deciduous) plus the timing (DOY) when the leaf-on and leaf-off periods occur are set $\left(s_{\text {start }} / s_{\text {stop }}\right.$ and $f_{\text {start }} /$

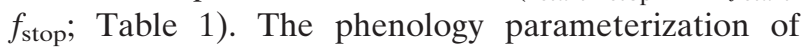
Loridan et al. (2011) is used to model the evolution of tree/shrub LAI through the year $\left(\mathrm{LAI}_{\text {tree }}\right)$. For the grass fraction $\left(\mathrm{LAI}_{\text {grass }}\right)$, a fixed LAI of 1.6 is assumed (Grimmond and Oke 1991). The portion of the vegetation that is active $\left(f_{\text {act }, v}\right)$ is defined as the ratio of the active vegetated surface [see Eq. (22)] to that covered by the fully grown vegetation $\left(s_{\text {stop }}<\mathrm{DOY}<f_{\text {start }}\right)$.

\section{c. The complete surface}

The urban fraction ( $f_{\text {urb }}$; Table 1$)$ weights the urban and vegetated fractions. Plan areas $P$ of each surface subcomponent are

$$
\begin{aligned}
P_{\text {urban }} & =W_{\text {roof }}\left(W_{\text {road }}+W_{\text {roof }}\right) ; \quad P_{\text {total }}=\frac{P_{\text {urban }}}{f_{\text {urb }}} \\
P_{\text {veg }} & =P_{\text {total }}\left(1-f_{\text {urb }}\right) ; \quad P_{\text {grass }}=f_{\text {grass }} P_{\text {veg }} ; \\
P_{\text {tree }} & =\left(1-f_{\text {grass }}\right) P_{\text {veg }} .
\end{aligned}
$$

Active surface indices $\left(\chi_{\text {built }} ; \chi_{\mathrm{veg}}\right)$ are derived as ratios of the active ( $\left.A_{\text {built }} ; A_{\text {veg }}\right)$ to the total $\left(S_{\text {total }}\right) 3 \mathrm{D}$ surface covers. The total active surface index $\left(\chi_{\text {tot }}\right)$ combines the two:

$$
\begin{aligned}
A_{\text {built }}= & \left(2 h_{\text {act }} Z_{R}+r_{\text {act }} W_{\text {roof }}+w_{\text {act }} W_{\text {road }}\right) W_{\text {roof }} \\
A_{\text {veg }}= & \mathrm{LAI}_{\text {tree }} P_{\text {tree }}+\mathrm{LAI}_{\text {grass }} P_{\text {grass }}, \\
S_{\text {total }}= & \left(4 Z_{R}+W_{\text {roof }}+W_{\text {road }}\right) W_{\text {roof }}+\mathrm{LAI}_{\text {max }} P_{\text {tree }} \\
& +\mathrm{LAI}_{\text {grass }} P_{\text {grass }}, \quad \text { and } \\
\chi_{\text {built }}= & \frac{A_{\text {built. }}}{S_{\text {total }}} ; \quad \chi_{\text {veg }}=\frac{A_{\text {veg }}}{S_{\text {total }}} ; \quad \chi_{\text {tot }}=\frac{A_{\text {built }}+A_{\text {veg }}}{S_{\text {total }}} .
\end{aligned}
$$

These surface ratios characterize the portion of the total surface actively involved in energy exchange with the atmosphere $\left(\mathrm{m}^{2} \mathrm{~m}^{-2}\right.$, dimensionless; i.e., likely to dissipate or store heat via means other than radiative fluxes). The site location, the urban geometry $\left(Z_{R}, W_{\text {roof }}\right.$, and $W_{\text {road }}$, and the vegetation type [minimum and maximum leaf area indices $\left(\mathrm{LAI}_{\min } ; \mathrm{LAI}_{\max }\right)$, leaf-on $\left(s_{\text {start }}\right.$; $\left.s_{\text {stop }}\right)$ and leaf-off $\left(f_{\text {start }} ; f_{\text {stop }}\right)$ periods; see Table 1], as well as the day of year and time of day, are all accounted for in this representation of the surface cover. A $\chi_{\text {tot }}$ value of 1 represents the extreme case of fully grown vegetation (grass field or $s_{\text {stop }}<$ DOY $<f_{\text {start }}$ ) and a flat urban surface $\left(Z_{R}=0\right)$. Consequently, this provides a robust alternative to the static plan area fractions presented in the introduction and used in many previous studies. The model is available online (see the acknowledgments).

\section{Surface-flux relations}

Table 1 lists the input values used to compute the active surface indices $\left(\chi_{\text {tot }}, \chi_{\text {built }}\right.$, and $\left.\chi_{\text {veg }}\right)$ [section 3; Eq. (24)]. From calculated time series of indices, the means are derived for the short-term or 2-monthly subsets of the midday ( $\pm 3 \mathrm{~h}$ at solar noon) ratios. In Fig. 6, $Q \uparrow / Q \downarrow$ and $\chi_{\text {tot }}$ are shown with error bars ( \pm 1 standard deviation) to indicate the variability. This enables analysis of the main features of the energy partitioning at the time of maximum heat input. Unlike Fig. 1, the annual subsets have distinct circuits in the surface ratios (rather than vertical lines) that show the energy partitioning evolution through the year: in winter, the active portion of the total surface cover is at its minimum $\left(\chi_{\text {tot }}<0.20\right.$ for Łódź, Helsinki, and Tokyo; $\chi_{\mathrm{tot}} \sim 0.35$ for Melbourne) and the ratio of the $Q \downarrow$ being dissipated back to the atmosphere as $Q \uparrow$ is considerably higher than in other months, whereas when the active portion of surface reaches its maximum with greater sun exposure and fully grown vegetation (spring and summer) there is a higher fraction of the $Q \downarrow$ dissipated via turbulent processes or stored. As a consequence, the $Q \uparrow / Q \downarrow$ ratio reaches its minimum $(\sim 0.55 Q \downarrow)$.

For Tokyo the spring/summer and the seasonality in $\chi_{\text {tot }}$ are in agreement with the other long-term datasets; the seasonality in $Q \uparrow / Q \downarrow$, however, is very limited with autumn/winter appearing as outliers. This can be explained by Moriwaki and Kanda's (2004) conclusions (section 2), which highlight the importance of the normal component of solar radiation for low-latitude sites in the winter. Given the same winter $K \downarrow$, the surface area exposed to radiation will be larger at a low-latitude site where the angle of incidence remains smaller than at a high-latitude site like Helsinki or Łódź. This is confirmed by the $\chi_{\text {tot }}$ of the two sites with lowest latitudes (Me93 and Ou03), where data were also collected in the winter. This highlights the need for more long-term (i.e., including wintertime) measurement campaigns at low latitudes. 


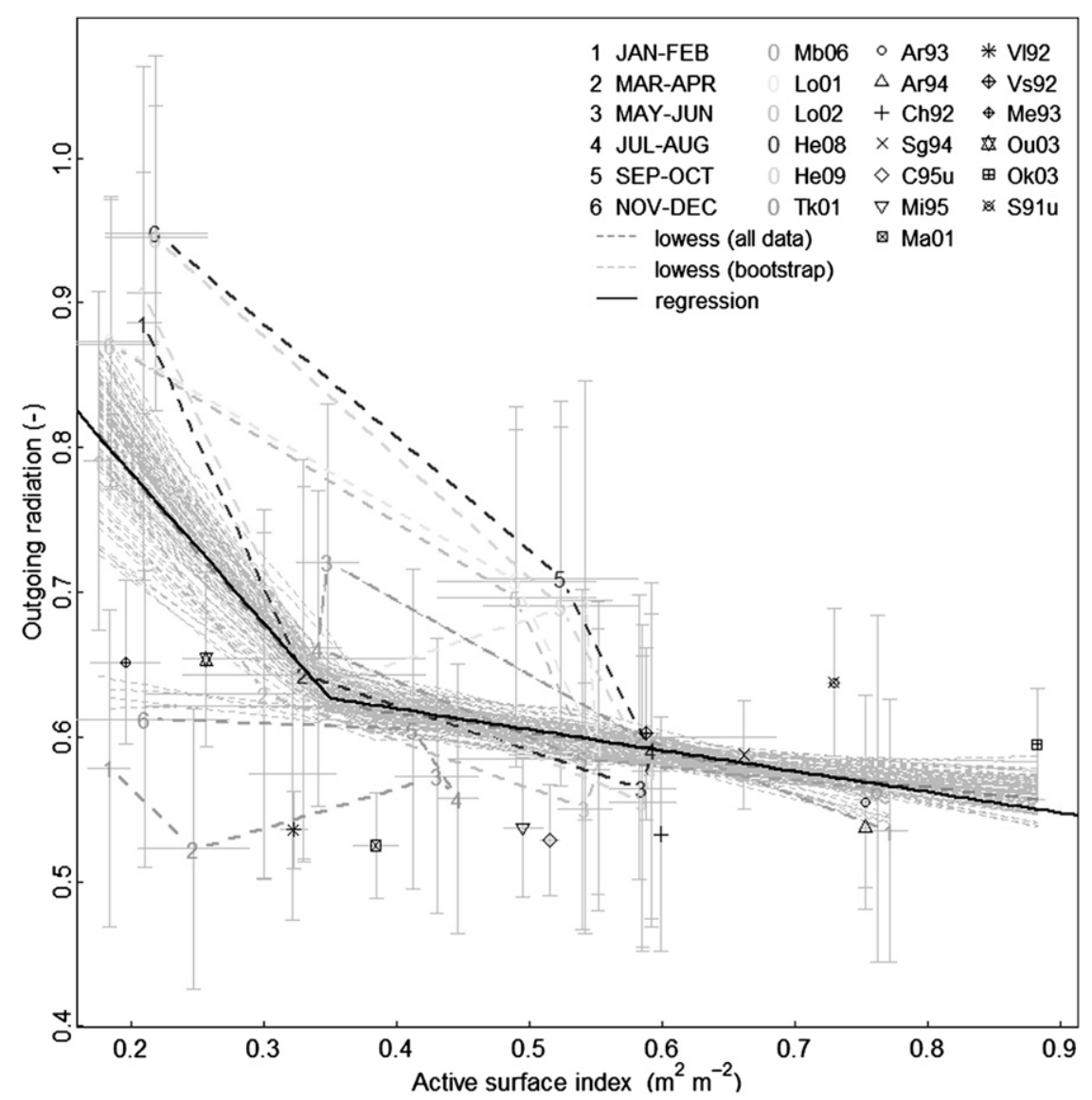

FIG. 6. The $Q \uparrow / Q \downarrow$ mean daytime (3 h around solar noon) ratio as a function of the mean midday $\chi_{\text {tot }}$ value for all short-term sites and 2-month subsets of the yearly sites. The LOWESS regression is shown by the dashed line that mostly overlies the black curve. Error bars show \pm 1 standard deviation. See text for details. The nonlinear regression (black curve) is Eq. (25).

The variability in $\chi_{\text {tot }}$, which is greatest for the spring and autumn months (Fig. 6), is due to rapid changes in sun elevation and vegetation phenology in these seasons as compared with winter or summer. It also appears to be more pronounced for high-latitude sites. The variability in flux ratio has a less obvious seasonal trend but the similarity of the two years of records in Łódź and Helsinki highlights the repeatability and confirms seasonality as a key driver to the flux partitioning. The variability of the short-term datasets is not as pronounced, with most data collected in the spring/summer season. Yet Me93 and Ou03, the only two measurement programs performed during the winter, show a similar pattern with higher $Q \uparrow / Q \downarrow$ ratios and lower $\chi_{\text {tot }}$.

With a LOWESS regression curve (Cleveland 1981; Fig. 6, dashed line that mostly overlies the black regression line) two different regimes are apparent: 1) a steep decrease of the $Q \uparrow / Q \downarrow$ ratio with increasing values of $\chi_{\text {tot }}$ up to a threshold of $\sim 0.35$ (mostly winter data) and 2) an almost constant (gentle) slope for $\chi_{\text {tot }}>0.35$.
This suggests that radiative transfers are most important when the surface is receiving the least direct radiation (low $\chi_{\text {tot }}$ ) relative to all other processes dissipating heat. To test the robustness of the LOWESS result, bootstrapping (Hinkley 1988) is applied: each resample (100 iterations) used 39 of the 49 points after 10 points were randomly removed prior to each LOWESS analysis. The resulting family of curves is plotted (Fig. 6, gray lines) to provide an indication of the spread. These confirm the two trends identified with the initial LOWESS simulation ( $4 \%$ of curves fail to show the break in slope). The widest spread is for low (winter) $\chi_{\text {tot }}$ ratios. The 100 curves are analyzed with nonlinear regression to derive a simple predictive relation for the midday $Q \uparrow / Q \downarrow$ ratio (Fig. 6, black curve):

$$
\begin{aligned}
\frac{Q \uparrow}{Q \downarrow}\left(\chi_{\text {tot }}\right)= & 1.04 \times \max \left(0.35-\chi_{\text {tot }}, 0\right) \\
& -0.15 \times \max \left(\chi_{\text {tot }}-0.35,0\right)+0.62
\end{aligned}
$$



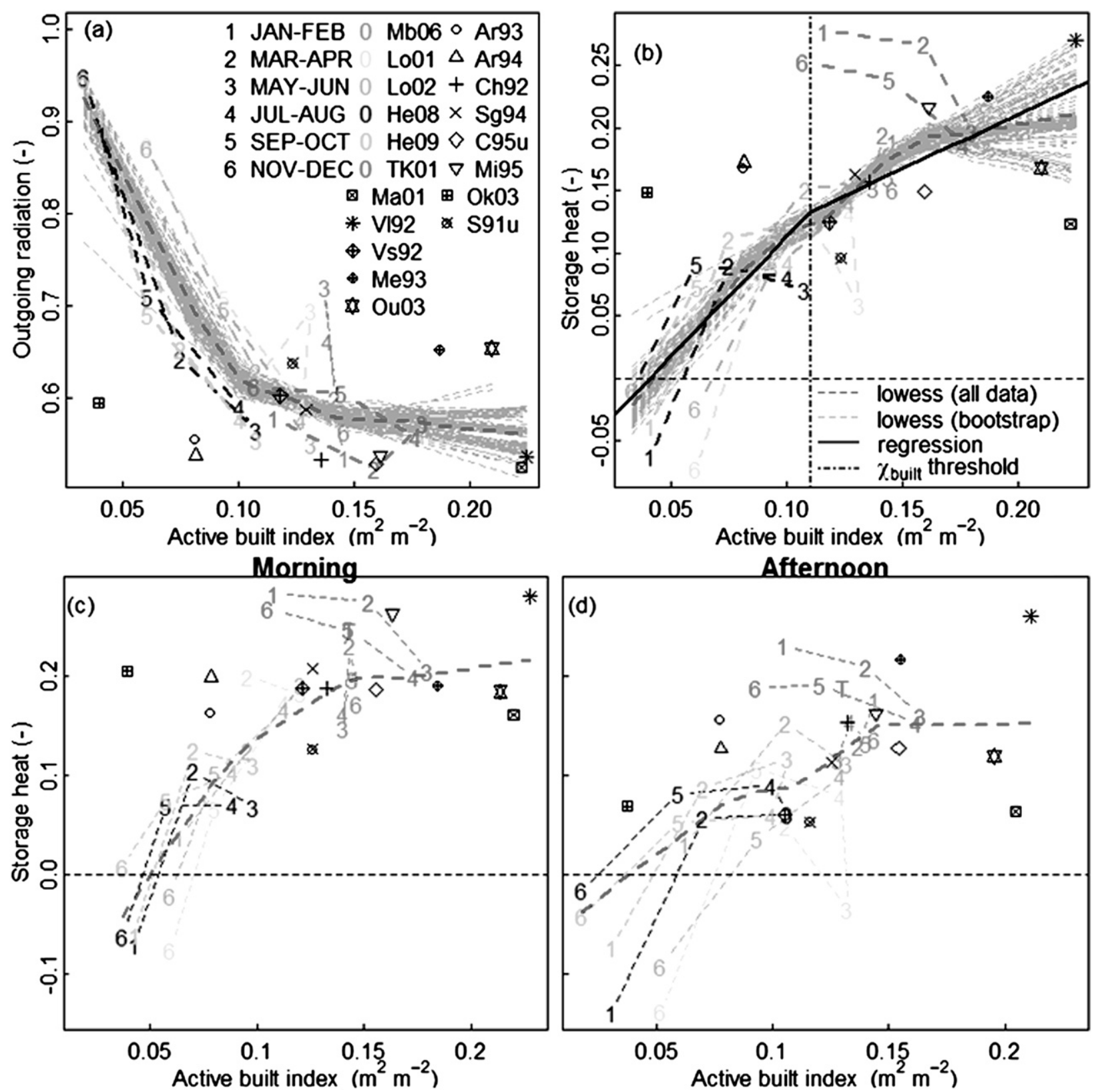

FIG. 7. The (top left) $Q \uparrow / Q \downarrow$ and (other panels) $\Delta Q_{S} / Q \downarrow$ means for the (a),(b) midday, (c) morning (2-3 h before solar noon), and (d) afternoon (2-3 h after solar noon) ratios as a function of the $\chi_{\text {built }}$ values averaged over the same periods. For (b) the nonlinear regression equation is Eq. (26).

To show how the use of the active index influences the surface-flux relation, $Q \uparrow / Q \downarrow$ is shown as a function of $\chi_{\text {built }}$ (Fig. 7a). Sites like Me93 and Ou03 with a relatively low $\chi_{\text {tot }}$ have comparatively higher $\chi_{\text {built }}$ ratios while $\mathrm{Ok} 03$ has gone in the other direction. The evolution of $\chi_{\text {built }}$ for Mb06 is very limited because of a low canyon height-to-width ratio $\left(Z_{R}=6.4 \mathrm{~m}, W_{\text {road }}=\right.$ $38.5 \mathrm{~m}$; Table 1). This suggests that $Q \uparrow / Q \downarrow$ is better characterized by the total surface ratio $\chi_{\text {tot }}$ (Fig. 6), which accounts for the vegetation contribution to radiative processes.

Obviously, some flux ratios are more closely linked to either the active built $\left(\chi_{\text {built }}\right)$ or vegetated $\left(\chi_{\text {veg }}\right)$ indices. The storage ratio $\Delta Q_{S} / Q \downarrow$ is influenced more by $\chi_{\text {built }}$ than $\chi_{\text {veg }}$ (Fig. 7b). For winter in Helsinki and Łódź, the ratio is negative, indicating some heat loss from the surface even during the day. This is due to a low solar receipt (high-latitude sites) and anthropogenic heating 

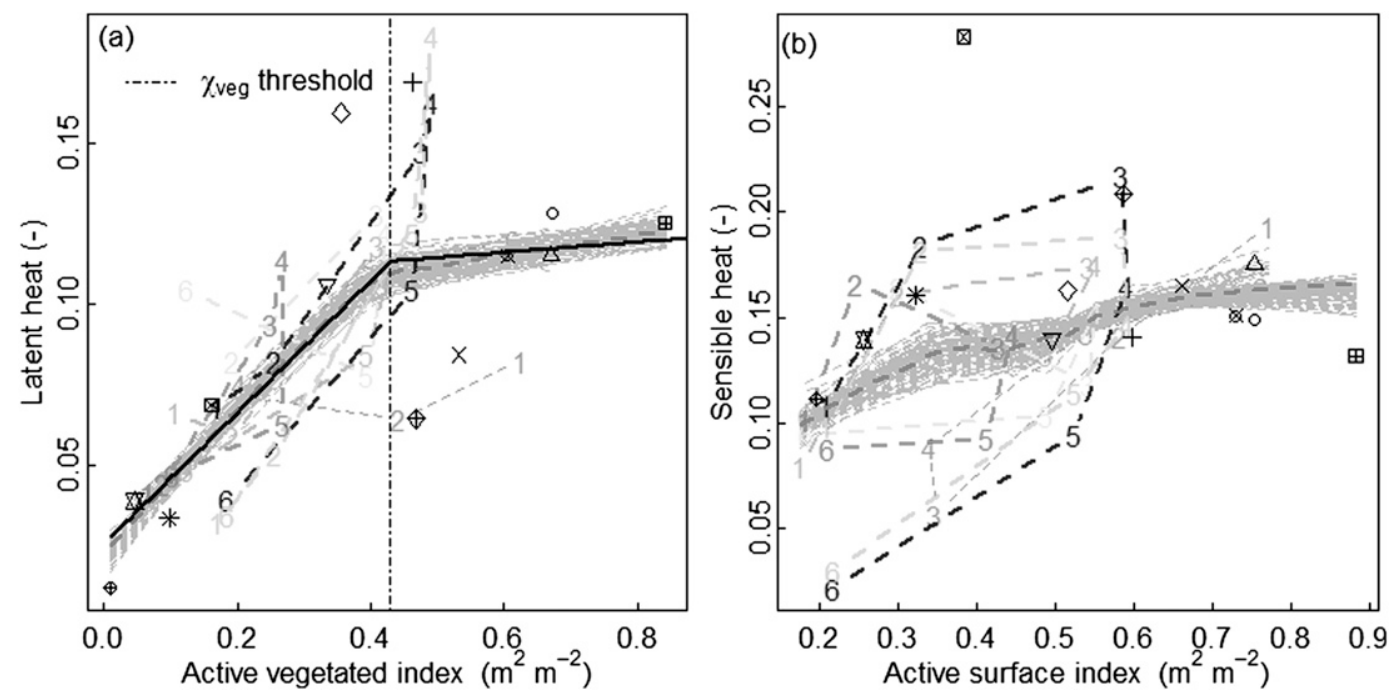

FIG. 8. Mean midday ratios of (a) $Q_{E} / Q \downarrow$ and (b) $Q_{H} / Q \downarrow$ as a function of the mean midday $\chi_{\mathrm{veg}}$ and $\chi_{\mathrm{tot}}$ values, respectively. The nonlinear regression (thick black line) for (a) is found in Eq. (27). For key, see Fig. 7.

of the urban fabric enhancing energy release. In addition to measurement errors, it should be remembered that the errors in $Q_{F}$ (here from LUCY) and/or the $\gamma$ and $\nu$ coefficients used in Eqs. (3) and (4) will have an impact. However, it does suggest that storage is less important for low $\chi_{\text {built }}$ values, which is consistent with our a priori expectations. When $\chi_{\text {built }}$ increases (i.e., toward the summer), a larger portion of $Q \downarrow$ is stored. The one noticeable exception is the case of Tk01, where the winter/ autumn storage ratios are far greater than could be expected from analysis of the rest of the data (see earlier paragraph and section 2). Overall, the LOWESS curves highlight an increasing trend in the data with a break in slope around $\chi_{\text {built }}=0.11$, which is obtained from nonlinear regression (Fig. 7b, black curve):

$$
\begin{aligned}
\frac{\Delta Q_{S}}{Q \downarrow}\left(\chi_{\text {built }}\right)= & -1.9 \times \max \left(0.11-\chi_{\text {built }}, 0\right) \\
& -0.89 \times \max \left(\chi_{\text {built }}-0.11,0\right)+0.13 .
\end{aligned}
$$

Variability in the storage ratio between sites with similar $\chi_{\text {built }}$ values is largest at high $\chi_{\text {built }}$ (Fig. 7b, gray dashed curves), which is likely attributable to material properties such as the heat capacity and conductivities differing from one site to the other. In particular, the V192, Ou03, and Ma01 sites all have $\chi_{\text {built }}$ values around 0.22 but are located at opposite ends of the LOWESS spread with a maximum storage ratio of $\sim 0.27$ for the industrial site V192 and values of $\sim 0.15$ for Ma01 and Ou03, where building materials offer better insulation (higher heat capacities). Similarly at low $\chi_{\text {built }}$, the $\mathrm{Ok} 03$ site, which is very sparsely built, has a higher storage ratio than would be expected from its $\chi_{\text {built }}$ value. This can be explained by the use of light wood construction materials with low heat capacities in the neighborhood (Anderson 2009). The presence of water bodies (e.g., Mi95) or extensive irrigation (e.g., Ar93, Ar94) also increases the storage capacity. Note that for Mb06 seasonal variations in $\chi_{\text {built }}$ are limited (restricted shading). A closer look at the contrast between morning ( $2-3 \mathrm{~h}$ before solar noon; Fig. 7c) and afternoon (2-3 h after solar noon; Fig. 7d) storage ratios provides additional evidence that material properties are important in such a classification (see Fig. 10 for additional considerations with regard to model limitations). The general tendency for all sites is toward a higher $\Delta Q_{S} / Q \downarrow$ in the morning than the afternoon (i.e., a hysteresis). The contrast with the afternoon data relates to the variety of heat capacity and conductivity values involved with the materials used (see Loridan and Grimmond 2011). Surfaces with low heat capacities (e.g., Ok03) store more energy in the first hours of exposure to sun but quickly reach saturation if they fail to conduct energy internally; better insulators have a lower morning storage ratio, which stays almost constant through the day.

The evolution of $Q_{E} / Q \downarrow$ is best explained by the active vegetated index $\chi_{\text {veg }}$ (Fig. 8a), while $Q_{H} / Q \downarrow$ responds to $\chi_{\text {tot }}$ (Fig. 8b). As expected, the $Q_{E} / Q \downarrow$ ratio increases with increasing $\chi_{\text {veg }}$ values. The LOWESS trends are composed of a steep linear increase below $\chi_{\text {veg }} \sim 0.43$ (vertical line) and a more gentle one after. For the two Chicago short-term sites (Ch92 and C95u), 
as well as the Helsinki sites in spring and summer, $Q_{E}$ is (0.15-0.2) $Q \downarrow$ but down to $\sim 00.1 Q \downarrow$ for most sites with a similar $\chi_{\text {veg. }}$ Such discrepancies can be explained by the omission of a key factor in our representation: water availability (Fig. 10). Provided with additional information, the two well-irrigated Chicago sites could for instance be assigned an enhanced $\chi_{\text {veg }}$ ratio to represent the unrestricted water availability (Grimmond and Oke 2002), while it could be reduced for campaigns involving dry conditions (e.g., Vs92). Information on the fraction of the vegetation that is irrigated (Grimmond et al. 1996; Grimmond and Oke 2002) could be included in the analysis. Based on nonlinear regression (Fig. 8a), a predictive relation for the midday $Q_{E} / Q \downarrow$ is derived:

$$
\begin{aligned}
\frac{Q_{E}}{Q \downarrow}\left(\chi_{\mathrm{veg}}\right)= & -0.2 \times \max \left(0.43-\chi_{\mathrm{veg}}, 0\right) \\
& -0.016 \times \max \left(\chi_{\mathrm{veg}}-0.43,0\right)+0.11 .
\end{aligned}
$$

The greater scatter of the $Q_{H}$ surface-flux relation results in the weakest trends in the LOWESS curves (Fig. 8b). The quantity $Q_{H} / Q \downarrow$ dissipates heat when the surface is active but water is not available in sufficient quantity for evaporation or heat cannot be conducted into the materials fast enough to enable further storage. Therefore, it probably is the most difficult to directly relate to a simple surface characteristic. A residual predictive relation can, however, be derived using Eqs. (5) and (25)-(27):

$$
\begin{aligned}
\frac{Q_{H}}{Q \downarrow}\left(\chi_{\text {tot }}, \chi_{\text {built }}, \chi_{\text {veg }}\right)= & 1-\frac{Q \uparrow}{Q \downarrow}\left(\chi_{\text {tot }}\right)-\frac{\Delta Q_{S}}{Q \downarrow}\left(\chi_{\text {built }}\right) \\
& -\frac{Q_{E}}{Q \downarrow}\left(\chi_{\text {veg }}\right) .
\end{aligned}
$$

Being a residual relation, the errors in Eqs. (25)-(27) will accumulate in Eq. (28).

The flux circuits in $Q_{E} / Q_{\downarrow}$ have a steep increase in spring and summer months for all sites except Mb06, which has a relatively low value in the January-February period (Fig. 8a). This may relate to very limited irrigation being permitted (Melbourne Water 2010), leading to stressed vegetation. This decrease in $Q_{E} / Q \downarrow$ appears to be mostly compensated for by an increase in $Q_{H} / Q \downarrow$ (Fig. 8b), which suggests the two turbulent fluxes are competing for the available energy with evaporation limited by water availability. This is demonstrated in Fig. 9 where the vegetation fraction (Fig. 1) is replaced with $\chi_{\text {veg. }}$. Sites with restricted water availability (e.g., Mb06 in January-April and Vs92) exhibit larger Bowen ratios than expected from the LOWESS simulation. The vertical lines (Fig. 1) are replaced by circuits (Fig. 9) through the use of $\chi_{\mathrm{veg}}$ as a predictor. The LOWESS curves, based on all the data (Fig. 9) rather than only summer data (Fig. 1), are approximated using nonlinear regression:

$$
\begin{aligned}
\frac{Q_{H}}{Q_{E}}\left(\chi_{\mathrm{veg}}\right)= & 3.8 \times \max \left(0.43-\chi_{\mathrm{veg}}, 0\right) \\
& -0.22 \times \max \left(\chi_{\mathrm{veg}}-0.43,0\right)+1.6
\end{aligned}
$$

Equation (29) underpredicts the Bowen ratio for some of the very low vegetated sites (e.g., Me93, V192, Ma01, or Tk01 in March-April) and has an upper bound of $Q_{H} / Q_{E}\left(\chi_{\mathrm{veg}}=0\right)=3.23$, which is considerably lower than the maximum mean midday value observed $\left(Q_{H} / Q_{E}>12\right.$ for Me93; Fig. 9). The very low evaporative fluxes associated with these sites have a considerable impact on the magnitude of the Bowen ratio; for example, a reduction from $Q_{E} \sim 50 \mathrm{~W} \mathrm{~m}^{-2}$ (e.g., Ou03; Table 2) to $Q_{E} \sim 15 \mathrm{~W} \mathrm{~m}^{-2}$ (e.g., Me93) is enough to generate the range observed in Fig. 9 if $Q_{H} \sim$ $200 \mathrm{~W} \mathrm{~m}^{-2}$. Again, this highlights the difficulties in predicting $Q_{H}$ from surface characteristics and suggests Eq. (29) should be used with caution for low vegetated sites (e.g., where $\chi_{\text {veg }}<0.2$ ).

With an estimate of the amount of incoming radiant energy $Q \downarrow$ [from observations or modeling; e.g., Offerle et al. (2003); Liston and Elder (2006); Loridan et al. (2011)] and the inclusion of the anthropogenic heat contribution to each flux following the methodology presented in Eqs. (3) and (4), the mean daytime ( $\pm 3 \mathrm{~h}$ at solar noon) flux magnitude can be predicted from Eqs. (25)-(27) plus either Eqs. (28) or (29) and knowledge of the surface cover (Table 1). These equations form the basis for the FRAISE scheme (see section 6). Although Eq. (28) accumulates the errors from Eqs. (25)-(27) into the predicted $Q_{H}$, it offers the advantage of energy balance closure. Equation (29), which does not close the SEB [i.e., Eq. (5) does not hold], should provide a better $Q_{H}$ estimate for sites with sufficient vegetation $\left(\chi_{\mathrm{veg}}>0.2\right)$. The predicted fluxes account for seasonal changes in the key processes controlling the surface-atmosphere energy exchange and do not require estimation of $Q^{*}$. They are only representative of daytime energy exchange.

Despite analysis of an extensive range of data, there is clearly a need to consider the types of environments for which observations are needed. Not all flux ratio-active index values are physically likely (Fig. 10) and gaps are apparent. Observation from a very humid urban site and/or where anthropogenic cooling via air conditioning is of importance (Moriwaki et al. 2008) would provide data with relatively low $\chi_{\text {veg }}$ ratios but a significant $Q_{E} / Q \downarrow$ component (see Fig. 10, and the example of the 


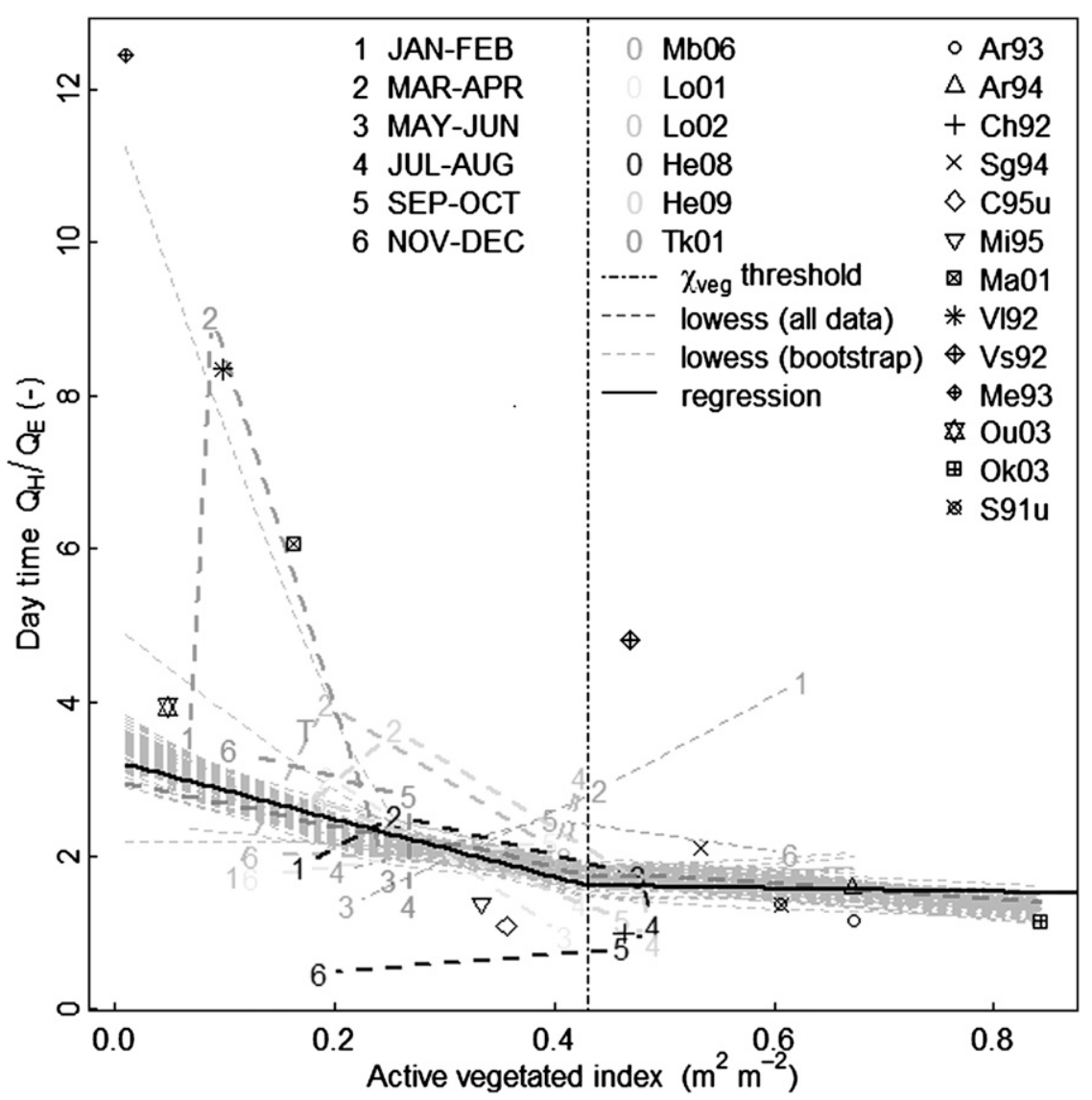

FIG. 9. Mean midday ( $\pm 3 \mathrm{~h}$ around solar noon) Bowen ratio $\left(Q_{H} / Q_{E}\right)$ as a function of the midday $\chi_{\text {veg }}$ value. The LOWESS regression is performed on all points (unlike Fig. 1). The nonlinear regression (thick black line) is found in Eq. (29).

two humid Chicago sites in Fig. 8a). Similarly, sites with a large fraction of wet bare soil (or water) could store more energy than expected from the derived $\chi_{\text {built }}{ }^{-}$ storage relation (e.g., Mi95, which contains relatively large amounts of water fractions).

\section{Potential for application in atmospheric models}

The discussion in section 4 suggests $\chi_{\text {tot }}$ is a good indicator of the $Q \downarrow$ fraction radiated back to the atmosphere, while the stored portion $\Delta Q_{S} / Q \downarrow$ appears to be
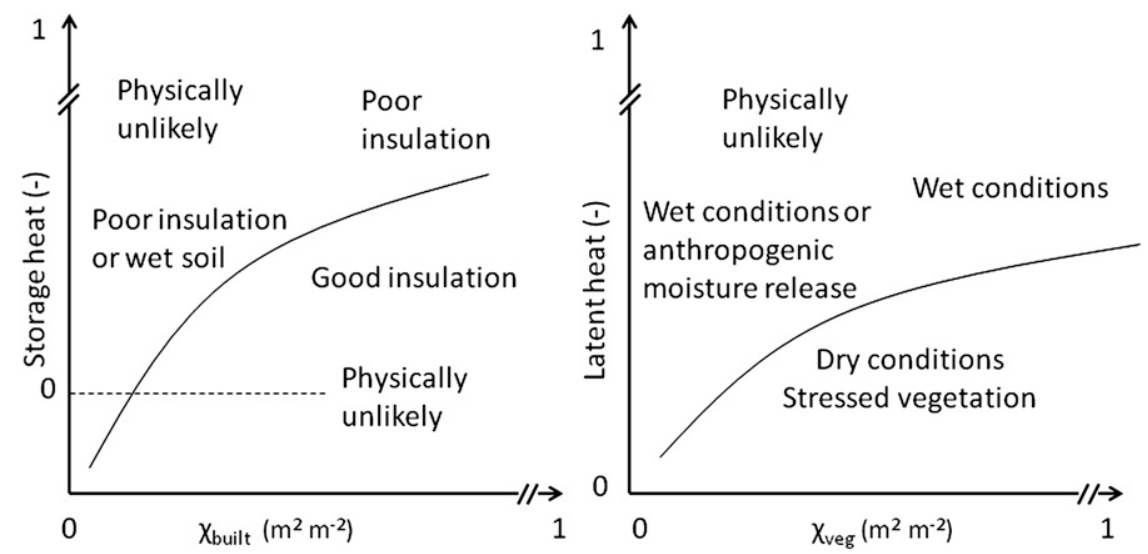

FIG. 10. Theoretical flux ratio-active index diagrams. 
better explained by $\chi_{\text {built }}$ and $Q_{E} / Q \downarrow$ by $\chi_{\text {veg. }}$. From such results, generalizations as to how the surface affects energy partitioning can be developed and applied to models designed for numerical weather prediction (NWP), regional climate modeling, or air quality forecasting. These have reached grid resolutions where intraurban heterogeneities need to be accounted for. Up to the order of several hundreds of urban grid cells can coexist within domains currently used (e.g., $10^{2}-10^{3} \mathrm{~km}^{2}$ with a grid resolution of $\sim 10^{\circ} \mathrm{km}^{2}$ in NWP). Based on our empirical understanding, and studies such as this, parameterizations of surface-atmosphere energy exchange can no longer be assumed to be identical for all urban cells. For this type of model, direct energy input into the land surface component occurs via the incoming solar and longwave contributions, and the primary task of the scheme is to partition this energy to provide the boundary condition energy fluxes to the atmosphere $\left(K \uparrow, L \uparrow, Q_{H}\right.$, and $\left.Q_{E}\right)$. Many of the current state-of-theart urban schemes account for the same sort of processes as the one presented in section 2 (e.g., shading patterns and phenology evolution) and should therefore be able to simulate energy partitioning when provided with input characteristics such as in Table 1. However, they often use default parameter values for "typical" urban environments (or urban classes) where no adequate information on the actual input parameter values are available (Flagg and Taylor 2011; Lee et al. 2011). In recent years questions have arisen as to the number of classes needed to represent intraurban heterogeneities without a drastic change in the amount of information required and/or the basis on which these classes should be defined.

For instance, the Weather Research and Forecasting (WRF) community model by default currently accounts for three types of urban environments (Chen et al. 2011; see their Table 1) based on the U.S. Geological Survey (USGS) National Land Cover Data classification (NLCD 2010): 1) low-intensity residential (LIR, where impervious surfaces account for $30 \%-80 \%$ of total cover), 2) high-intensity residential (HIR, $80 \%-100 \%$ of the total cover), and 3) commercial-industrial (C-I; others not classified as HIR). Stewart and Oke's (2009) thermal climate zone scheme separates urban (or "highly disturbed") environments into nine subclasses based on their built surface fraction, building height-to-width ratio, sky-view factor, height of roughness elements, anthropogenic heat flux, and surface thermal admittance. Although these descriptive classifications are relatively intuitive and easy to refer to, they do not explicitly relate the environment to the type of energy partitioning it generates. Consequently, two sites morphologically different but producing similar energy fluxes would belong to two distinct categories, while two similar sites leading to considerable difference in the boundary condition energy fluxes they release to the atmosphere could belong to the same category.

Here, we suggest a classification of urban environments, designed for atmospheric modeling applications, should be able to distinguish urban areas in terms of how they partition incoming energy $Q \downarrow$. The generalized surface flux relations (section 4) provide a good alternative to current classification methods, through highlighting the key characteristics of the environment that are important to defining classes.

With the objective of defining classes, threshold values $\left(\chi_{\text {built }}=0.11 ; \chi_{\text {veg }}=0.43\right)$ are identified from the surfaceflux relations (Figs. $7 \mathrm{~b}$ and $8 \mathrm{a}$ ). Both correspond to transition points in the respective LOWESS trends. From these two thresholds, four categories, or urban zones for characterizing energy partitioning (UZE), are distinguished (Fig. 11):

1) both $\chi_{\text {built }}$ and $\chi_{\text {veg }}$ below the threshold values (winter conditions)—only occurs in Łódź between September and April, in Helsinki between November and April, and in November-December in Tokyo;

2) $\chi_{\text {built }}<0.11$ but $\chi_{\text {veg }}>0.43$ (low density) - Ok03, Ar93, Ar94, and Helsinki between May and October belong to this category;

3) both $\chi_{\text {built }}$ and $\chi_{\text {veg }}$ exceed the thresholds (medium density)—Ch92, Vs92, Sg94, S91u, and Mb06 from November to April; and

4) $\chi_{\text {built }}>0.11$ but $\chi_{\text {veg }}<0.43$ (high density)—C95u, Mi95, Ma01, V192, Me93, Ou03, and Ló01 and Ló02 from May to August; Mb06 from May to October; and Tokyo from January to October all fall into this category.

Mean midday flux ratio values within each category (Fig. 11, capital letters) are plotted as a function of the mean $\chi_{\text {built }}$. The corresponding mean $\chi_{\text {veg }}$ and $\chi_{\text {tot }}$ are also shown for each of the four classes (Fig. 11, lowercase letters). Characterized by the lowest active surface fractions $\left(\chi_{\mathrm{tot}}=0.27, \chi_{\mathrm{veg}}=0.20, \chi_{\text {built }}=0.07\right)$, class 1 accounts for sites where most of the incoming energy is radiated back to the atmosphere (mean $Q \uparrow / Q \downarrow=0.756$ ) rather than stored (mean $\Delta Q_{S} / Q \downarrow=0.062$ ) or dissipated back via turbulent processes (mean $Q_{H} / Q \downarrow=0.115$; mean $\left.Q_{E} / Q \downarrow=0.066\right)$. The distinct characteristic of class 2 areas is their large $\chi_{\text {veg }}$ value (all exceed the threshold value, mean $\chi_{\mathrm{veg}}=0.56$ ); therefore, a much greater portion of the surface becomes active $\left(\chi_{\text {tot }}=\right.$ 0.64). The most direct impact is to the mean $Q \uparrow / Q \downarrow$ ratio, which decreases to 0.59 as the other methods of energy transfer start to be more significant. In particular, the relative portion of $Q \downarrow$ dissipated as $Q_{E}$ is doubled 


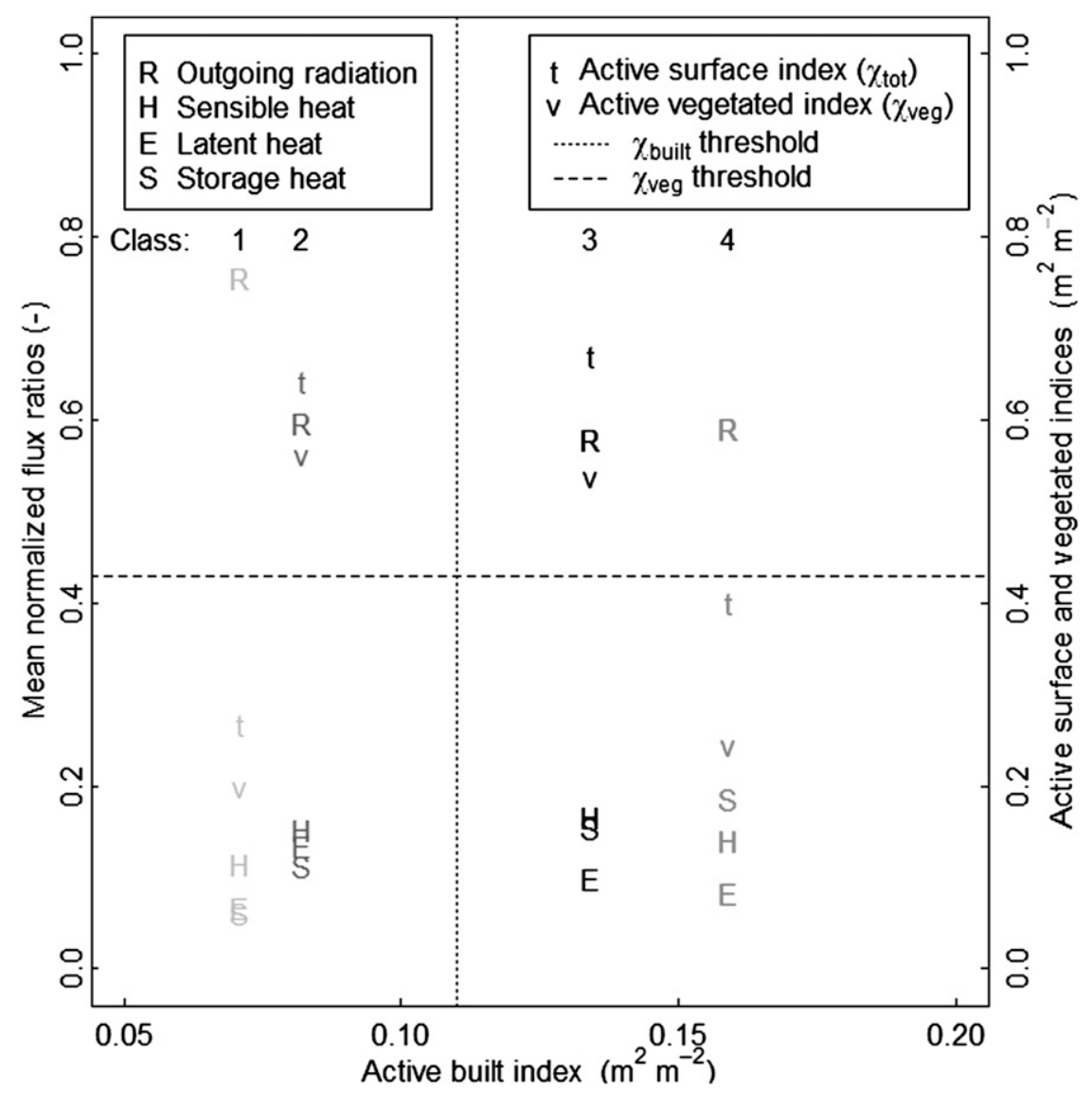

FIG. 11. Mean midday flux ratios (capital letters) and indices (lowercase letters and $x$ axis) characterizing the four urban classes (see text for class definition): 1) low active surface (winter), 2) most vegetated (low density), 3) more urban (medium density), and 4) most urban (high density).

(mean $Q_{E} / Q \downarrow=0.14$ ) and becomes comparable to the $Q_{H}$ portion (mean $Q_{H} / Q \downarrow=0.155$ ). The mean $\Delta Q_{S} / Q \downarrow$ increases to 0.12 . When the $\chi_{\text {built }}$ ratio reaches its threshold (i.e., classes 3 and 4), the fraction of incoming energy that is stored in the fabric becomes similar (class 3: mean $\Delta Q_{S} / Q \downarrow=0.16$ ) or greater than (class 4: mean $\left.\Delta Q_{S} / Q \downarrow=0.186\right)$ the portion dissipated via turbulent processes. The distinguishing differences in $\chi_{\mathrm{veg}}$ (decrease from 0.54 to 0.24 , classes 3 and 4, respectively) are not surprisingly associated with a decrease in mean $Q_{E} / Q \downarrow$ ratio (from 0.1 to 0.083 ) and even in $Q_{H} / Q \downarrow$ (from 0.17 to 0.14). The portion of energy being radiated back also increases as a consequence of the mean $\chi_{\text {veg }}$ reduction.

Although based on surface characteristics, the four categories also differ in the way they should impact the boundary condition energy fluxes in an atmospheric model. They cover most of the cases presented in Table 2 and therefore the energy partitioning patterns observed in urban environments to date (see caveats at the end of section 4). Some permutations of the flux ratios are not represented (e.g., $Q_{E}$ contribution exceeding both $Q_{H}$ and $\Delta Q_{S}$ ) but this is not common in urban environments and would probably fit in another category without drastic changes in their impacts on boundary condition energy fluxes (e.g., class 2).

When considering intraurban heterogeneities, such as in a NWP modeling system, grid cells previously considered as urban could now be redefined as falling into one of the classes in Fig. 11. A switch from a class-4 cell (highly urbanized) to a class-2 one (more vegetated) should, for instance, lead on average, to an additional $6 \%$ of the midday $Q \downarrow$ being evaporated into the atmosphere rather than stored. This assumes that the urban land surface scheme can reproduce such a switch in the energy partitioning when provided with the default parameter values characterizing a particular class. The way to calculate these default input parameter values for the Single Layer Urban Canopy (SLUCM) model (Kusaka et al. 2001; Kusaka and Kimura 2004; Loridan et al. 2010) with regard to its application in the WRF modeling 
TABLE 3. Evaluation of the FRAISE predictive relations [Eqs. (25)-(29) and (24)] with BUBBLE (Christen and Vogt 2004; Rotach et al. 2004) data. Note the ratios correspond to those presented in Eq. (5), while the flux estimates include the $Q_{F}$ contribution. Averaging windows differ from the ones used in Christen and Vogt (2004, their Table 5). Here, $P$ and $O$ indicate predicted and observed, respectively.

\begin{tabular}{|c|c|c|c|}
\hline Site & BSPR & BSPA & ALLS \\
\hline$f_{\text {urb }}$ & 0.84 & 0.69 & 0.47 \\
\hline$Z_{R}$ & 14.6 & 12.5 & 7.5 \\
\hline$W_{\text {roof }}$ & 11.2 & 14.8 & 11.9 \\
\hline$W_{\text {road }}$ & 20.2 & 17.2 & 17.5 \\
\hline Mean daytime $Q \downarrow\left(\mathrm{W} \mathrm{m}^{-2}\right)$ & 949.1 & 1038.2 & 1029.4 \\
\hline$\chi_{\text {tot }}$ & 0.419 & 0.578 & 0.761 \\
\hline$\chi_{\text {built }}$ & 0.183 & 0.130 & 0.085 \\
\hline$\chi_{\text {veg }}$ & 0.237 & 0.449 & 0.677 \\
\hline Urban class (UZE) & $\begin{array}{c}4=\text { most urban: } \\
\text { high density }\end{array}$ & $\begin{array}{l}3=\text { most urban: } \\
\text { medium density }\end{array}$ & $\begin{array}{c}2=\text { most vegetated: } \\
\text { low density }\end{array}$ \\
\hline$Q \uparrow / Q \downarrow(P / O)$ & $0.610 / 0.586$ & $0.586 / 0.548$ & $0.558 / 0.580$ \\
\hline$\widetilde{\Delta} Q_{S} / Q \downarrow(P / O)$ & $0.195 / 0.116$ & $0.147 / 0.142$ & $0.082 / 0.133$ \\
\hline$Q_{E} / Q \downarrow(P / O)$ & $0.072 / 0.090$ & $0.110 / 0.090$ & $0.115 / 0.128$ \\
\hline$Q_{H} / Q_{E}(P / O)$ & $2.335 / 2.458$ & $1.596 / 2.43$ & $1.546 / 1.295$ \\
\hline Mean daytime $Q^{*}(P / O)\left(\mathrm{W} \mathrm{m}^{-2}\right)$ & $366.5 / 416.8$ & $426.4 / 485.9$ & $450.6 / 448.0$ \\
\hline Mean daytime $Q_{E}(P / O)\left(\mathrm{W} \mathrm{m}^{-2}\right)$ & $67.8 / 85.1$ & $114.7 / 91.5$ & $117.4 / 131.4$ \\
\hline Mean daytime $\Delta Q_{S}(P / O)\left(\mathrm{W} \mathrm{m}^{-2}\right)$ & 186.3/128.9 & $154.8 / 161.1$ & $85.9 / 148.6$ \\
\hline Mean daytime $Q_{H}\left[P\left(\right.\right.$ Eq. 29)/O] $\left(\mathrm{W} \mathrm{m}^{-2}\right)$ & $159.7 / 202.8$ & $184.5 / 233.3$ & $182.8 / 168.1$ \\
\hline Mean daytime $Q_{H}\left[P\right.$ (Eq. (28)] $\left(\mathrm{W} \mathrm{m}^{-2}\right)$ & 119.7 & 164.2 & 254.6 \\
\hline
\end{tabular}

system is considered in a companion paper (Loridan and Grimmond 2011). The ability of an urban scheme to reproduce energy-partitioning patterns from a given class when provided with adequate input parameters can also be considered to be an evaluation procedure, or a test of its suitability for application in atmospheric models.

\section{Evaluation of the proposed classes and the FRAISE scheme}

To evaluate the applicability of the proposed classes and predictive relations, three independent datasets from the BUBBLE experiment (Christen and Vogt 2004; Rotach et al. 2004) are analyzed: dense urban (BaselSperrstrasse, BSPR), dense urban (Basel-Spalenring BSPA), and suburban (Allschwil-Ramelstrasse ALLS). The FRAISE scheme, which is summarized by Eqs. (25)(27) and (29), plus Eq. (24) for the surface ratios, was applied at each site.

Table 3 gives the FRAISE computed active surface ratios for each site during the intensive observation period (June-July 2002). Using these ratios, the sites are classified (section 5) into different categories: BSPR assigned to class 4 (most urban), BSPA to class 3 (more vegetated), and ALLS to class 2 (most vegetated). This result is consistent with the description given in Christen

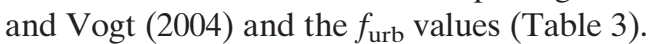

FRAISE also calculates the midday flux ratios. Using mean midday values of $Q \downarrow$ (from the observations) over the period and an estimation of $Q_{F}$ from LUCY $\left(Q_{F}=\right.$ $7 \mathrm{~W} \mathrm{~m}^{-2}$ ), an estimate of mean midday flux values can be derived (Table 3). For the two most urban sites (BSPR and BSPA), FRAISE tends to overestimate the $Q \uparrow$ ratio, which leads to an underestimation of the $Q^{*}$ component. For the most vegetated site (ALLS), the agreement is better. Note that the lower flux values at BSPR are due to a lower $Q \downarrow$ exposure during the period. The Bowen (and $Q_{E}$ ) ratios are predicted well for BSPR and ALLS, while it is underestimated for BSPA (evaporation is overpredicted). FRAISE estimates of $\Delta Q_{S} / Q \downarrow$ have greater intersite variability than observed (overestimation, BSPR: underestimation, ALLS). As the observed $\Delta Q_{S}$ is the residual of the SEB, it contains the net errors. As mentioned earlier, the $Q_{H}$ estimate based on the predicted Bowen ratio [i.e., Eq. (29)] does not ensure closure of the SEB; however, it predicts values that are in better agreement with observations than when Eq. (28) is used. These daytime flux values can also be related to the values provided in Table 5 of Christen and Vogt (2004) although no direct comparison is possible given the differences in the midday windows used. This analysis suggests that the general magnitude of the predicted midday fluxes is in the same range as the observed ones and extends the applicability of the FRAISE predictive relations outside of the range of sites studied here (i.e., Table 1).

\section{Conclusions}

Evaluation of urban energy flux partitioning using the incoming radiation $Q \downarrow$ rather than the previously used 
net all-wave radiation $Q^{*}$ ensures that surfaces radiative characteristics can be separated from the other controls/ processes.

A conceptual model of the active surface for energy exchange is introduced to allow for urban surface-flux relations to be interpreted. With the inclusion of shading patterns within city streets and vegetation phenology, the responses to seasonal variability across the latitudinal range of where data have been collected are considered. The analysis of flux measurements from 17 sites worldwide shows good relations between the portion of the incoming energy radiated back to the atmosphere and the total active surface index [decreasing function; see Eq. (25)], the portion of the incoming energy that is stored and the active built index [increasing function; see Eq. (26)], and between the portion of the incoming energy dissipated as latent heat and the active vegetated index [increasing function; see Eq. (27)]. The portion of incoming energy being dissipated as turbulent sensible heat does not relate well when directly compared to the active surface indices but can be derived as a residual [Eq. (28)] or inferred from the prediction of the Bowen ratio using the active vegetated index [Eq. (29)]. Combining these relations with an estimate of the anthropogenic heat $Q_{F}$ (e.g., from the LUCY model; Allen et al. 2011) and of the amount of incoming radiant energy $Q \downarrow$ provides the basis for a very simple parameterization scheme for predicting mean midday ( $\pm 3 \mathrm{~h}$ at solar noon) flux ratio values at locations where surface cover information (Table 1) is available. This Flux Ratio-Active Index Surface Exchange scheme can provide a range of end users (e.g., urban planners) with a very simple tool to (i) estimate the magnitude of outgoing energy fluxes to expect from a given neighborhood at the time of maximum solar exposure and (ii) assess the impacts of landscape modifications such as the inclusion of trees or other urban greenspaces.

From these relations and the active index threshold values, it is determined that the appropriate number of urban zones to characterize energy exchanges (UZE) in cities is four (Fig. 11). The mean flux ratio values for each class are analyzed and found to differ in terms of both surface characteristics and partitioning of energy. The application of UZE to atmospheric modeling is highlighted, where a classification of urban environments is needed to characterize heterogeneities in boundary condition energy fluxes across urban domains while restricting the number of classes.

The complete FRAISE system is tested independently using data from Basel (Christen and Vogt 2004). This provides a UZE classification for each site and correctly calculates the midday flux partitioning.
Although the concept of an active surface enables explanation of most of the flux partitioning processes, some additional features need to be included in future developments; namely, water availability (the active vegetation index could account for irrigation status, allowing very dry or very wet conditions to be reflected in vegetation portion being more-less inactive) and the types of materials used in an area, or more precisely the typical conductivity and heat capacity values within the measurement footprint, could help to refine the active built index. However, these require better documentation of both water-use habits during measurement campaigns and typical materials, which are typically not readily available.

Despite the extensive range of data analyzed, some types of urban environments still have not been included (Fig. 10). Results from measurement campaigns covering such cases are much needed and of interest to help us further investigate the relevance of surface active indices as indicators of flux partitioning. The need for more long-term datasets is also highlighted.

Acknowledgments. We thank Leena Järvi, Annika Nordbo, Timo Vesala, Brian Offerle, Andrew Coutts, Jason Berringer, Andreas Christen, Roland Vogt, Ryo Moriwaki, Manabu Kanda, and all those involved in the collection and processing of the flux data. We are grateful to Dr. Kusaka for his advice on the computation of the shadow patterns. Financial support for this project was provided by the National Science Foundation Grant ATM-0710631 and EU FP7-ENV-2007-1 BRIDGE (211345) and MEGAPOLI (212520). An R version of the FRAISE scheme is available online (http://geography. $\mathrm{kcl} . \mathrm{ac} . \mathrm{uk} / \mathrm{micromet} / \mathrm{index} \cdot \mathrm{htm})$. This includes the capability to determine the UZE independently.

\section{REFERENCES}

Allen, L., F. Lindberg, and C. S. B. Grimmond, 2011: Global to city scale urban anthropogenic heat flux: Model and variability. Int. J. Climatol., 31, 1990-2005.

Anderson, V., 2009: The exacerbation of anthropogenic heat fluxes as a function of interior climate controls and building envelope. M.S. thesis, Atmospheric Science Program, Indiana University, Bloomington, IN.

Arnfield, A. J., 2003: Two decades of urban climate research: A review of turbulence, exchanges of energy and water, and the urban heat island. Int. J. Climatol., 23, 1-26.

Chen, F., and Coauthors, 2011: The integrated WRF/urban modeling system: Development, evaluation, and applications to urban environmental problems. Int. J. Climatol., 31, 273-288.

Christen, A., and R. Vogt, 2004: Energy and radiation balance of a central European city. Int. J. Climatol., 24, 1395-1421.

Cimorelli, A. J., and Coauthors, 2005: AERMOD: A dispersion model for industrial source applications. Part I: General model 
formulation and boundary layer characterization. J. Appl. Meteor., 44, 682-693.

Cleveland, W. S., 1981: LOWESS: A program for smoothing scatterplots by robust locally weighted regression. Amer. Stat., 35, 54 .

Coutts, A. M., J. Beringer, and N. J. Tapper, 2007a: Characteristics influencing the variability of urban $\mathrm{CO}_{2}$ fluxes in Melbourne, Australia. Atmos. Environ., 41, 51-62.

$\longrightarrow, \ldots$, and $—$, 2007b: Impact of increasing urban density on local climate: Spatial and temporal variations in the surface energy balance in Melbourne, Australia. J. Appl. Meteor., 46, 477-493.

Flagg, D. D., and P. A. Taylor, 2011: Sensitivity of mesoscale model urban boundary layer meteorology to the scale of urban representation. Atmos. Chem. Phys., 11, 2951-2972.

Grimmond, C. S. B., 1992: The suburban energy balance: Methodological considerations and results for a mid-latitude west coast city under winter and spring conditions. Int. J. Climatol., 12, 481-497.

, 2006: Progress in measuring and observing the urban atmosphere. Theor. Appl. Climatol., 84, 3-22.

—_, and T. R. Oke, 1991: An evapotranspiration-interception model for urban areas. Water Resour. Res., 27, 1739-1755.

— and - 1995: Comparison of heat fluxes from summertime observations in the suburbs of four North American cities. J. Appl. Meteor., 34, 873-889.

$\longrightarrow$, and — 1999: Aerodynamic properties of urban areas derived from analysis of surface form. J. Appl. Meteor., 38, 12611292.

$\longrightarrow$, and _ 2002: Turbulent heat fluxes in urban areas: Observations and a Local-Scale Urban Meteorological Parameterization Scheme (LUMPS). J. Appl. Meteor., 41, 792-810.

,$- \ldots$, and H. A. Cleugh, 1993: The role of "rural" in comparisons of observed suburban-rural flux differences. Exchanges Processes at the Land Surface for a Range of Space and Time Scales: Proceedings of the Yokohama Symposium, IAHS Publ. 212, 165-174.

— C. Souch, H. Grant, and G. Heisler, 1994: Local scale energy and water exchanges in a Chicago neighbourhood. Chicago's Urban Forest Ecosystem: Results of the Chicago Urban Forest Climate Project, USDA Forest Service Northeastern Forest Experiment Station General Tech. Rep. NE-186, 201 pp. [Available online at http://www.treesearch.fs.fed.us/pubs/ 4285.]

,$- \ldots$, and M. Hubble, 1996: The influence of tree cover on summertime energy balance fluxes, San Gabriel Valley, Los Angeles. Climate Res., 6, 45-57.

— J. A. Salmond, T. R. Oke, B. Offerle, and A. Lemonsu, 2004a: Flux and turbulence measurements at a densely builtup site in Marseille: Heat, mass (water and carbon dioxide) and momentum. J. Geophys. Res., 109, D24101, doi:10.1029/ 2004JD004936.

- H.-B. Su, B. Offerle, B. Crawford, S. Scott, S. Zhong, and C. Clements, 2004b: Variability of sensible heat fluxes in a suburban area of Oklahoma City. Preprints, Symp. on Planning, Nowcasting, and Forecasting in the Urban Zone, Eighth Symp. on Integrated Observing and Assimilation Systems for Atmosphere, Oceans, and Land Surface, Seattle, WA, Amer. Meteor. Soc., J7.2. [Available online at http://ams.confex.com/ ams/pdfpapers/67542.htm.]

Grossman-Clarke, S., J. A. Zehnder, T. Loridan, and C. S. B. Grimmond, 2010: Contribution of land use changes to nearsurface air temperatures during recent summer heat events in the Phoenix metropolitan area. J. Appl. Meteor. Climatol., 49, 1649-1664.

Hinkley, D. V., 1988: Bootstrap methods (with discussion). J. Roy. Stat. Soc., 50B, 312-337, 355-370.

Kanda, M., R. Moriwaki, M. Roth, and T. R. Oke, 2002: Areaaveraged sensible heat flux and a new method to determine zero plane displacement length over an urban surface using scintillometry. Bound.-Layer Meteor., 105, 177-193.

King, T., and S. Grimmond, 1997: Transfer mechanisms over an urban surface for water vapor, sensible heat, and momentum. Preprints, 12th Symp. on Boundary Layers and Turbulence, Vancouver, BC, Canada, Amer. Meteor. Soc., 455-456.

Kusaka, H., and F. Kimura, 2004: Thermal effects of urban canyon structure on the nocturnal heat island: Numerical experiment using a mesoscale model coupled with an urban canopy model. J. Appl. Meteor., 43, 1899-1910.

—, H. Kondo, Y. Kikegawa, and F. Kimura, 2001: A simple single-layer urban canopy model for atmospheric models: Comparison with multi-layer and slab models. Bound.-Layer Meteor., 101, 329-358.

Lee, S.-H., and Coauthors, 2011: Evaluation of urban surface parameterizations in the WRF model using measurements during the Texas Air Quality Study 2006 field campaign. Atmos. Chem. Phys., 11, 2127-2143.

Liston, G. E., and K. Elder, 2006: A Meteorological Distribution System for High-Resolution Terrestrial Modeling (MicroMet). J. Hydrometeor., 7, 217-234.

Loridan, T., and C. S. B. Grimmond, 2011: Multi-site evaluation of an urban land-surface model: Intra-urban heterogeneity, seasonality and parameter complexity requirements. Quart. J. Roy. Meteor. Soc., doi: 10.1002/qj.963, in press.

_- and Coauthors, 2010: Trade-offs and responsiveness of the single-layer urban canopy parameterization in WRF: An offline evaluation using the MOSCEM optimization algorithm and field observations. Quart. J. Roy. Meteor. Soc., 136, 9971019.

— C. S. B. Grimmond, B. Offerle, D. T. Young, T. E. L. Smith, L. Järvi, and F. Lindberg, 2011: Local-Scale Urban Meteorological Parameterization Scheme (LUMPS): Longwave radiation parameterization and seasonality related developments. J. Appl. Meteor. Climatol., 50, 185-202.

McCarthy, M. P., M. J. Best, and R. A. Betts, 2010: Climate change in cities due to global warming and urban effects. Geophys. Res. Lett., 37, L09705, doi:10.1029/2010GL042845.

Melbourne Water, cited 2010; Melbourne Water home page. [Available online at http://www.melbournewater.com.au/.]

Moriwaki, R., and M. Kanda, 2004: Seasonal and diurnal fluxes of radiation, heat, water vapor, and carbon dioxide over a suburban area. J. Appl. Meteor., 43, 1700-1710.

,-- H. Senoo, A. Hagishima, and T. Kinouchi, 2008: Anthropogenic water vapor emissions in Tokyo. Water Resour. Res., 44, W11424, doi:10.1029/2007WR006624.

Newton, T., 1999: Energy balance fluxes in a subtropical city: Miami, FL. M.S. thesis, Dept. of Geography, University of British Columbia, Vancouver, BC, Canada, $140 \mathrm{pp}$.

— T. R. Oke, C. S. B. Grimmond, and M. Roth, 2007: The suburban energy balance in Miami, Florida. Geogr. Ann., 89A, 331-347.

NLCD, cited 2010: Multi-Resolution Land Characteristics Consortium (MRLC). [Available online at http://www.epa.gov/ mrlc/definitions.html.]

Offerle, B., C. S. B. Grimmond, and T. R. Oke, 2003: Parameterization of net all-wave radiation for urban areas. J. Appl. Meteor., 42, 1157-1173. 
, P. Jonsson, I. Eliasson, and C. S. B. Grimmond, 2005: Urban modification of the surface energy balance in the West African Sahel: Ouagadougou, Burkina Faso. J. Climate, 18, 39833995.

- C. S. B. Grimmond, K. Fortuniak, K. Klysic, and T. R. Oke, 2006: Temporal variations in heat fluxes over a central European city centre. Theor. Appl. Climatol., 84, 103116.

— I. Eliasson, C. S. B. Grimmond, and B. Holmer, 2007: Surface heating in relation to air temperature, wind and turbulence in an urban street canyon. Bound.-Layer Meteor., 122, 273-292.

Oke, T. R., 1978: Boundary Layer Climates. Routledge, 435 pp.

—, 1988: The urban energy balance. Prog. Phys. Geogr., 12, 471-508.

— , R. Spronken-Smith, E. Jauregui, and C. S. B. Grimmond, 1999: Recent energy balance observations in Mexico City. Atmos. Environ., 33, 3919-3930.

Oleson, K. W., G. B. Bonan, and J. Feddema, 2010: The effects of white roofs on urban temperature in a global climate model. Geophys. Res. Lett., 37, L03701, doi:10.1029/2009GL042194.

Pérez, C., P. Jiménez, O. Jorba, M. Sicard, and J. M. Baldasano, 2006: Influence of the PBL scheme on high-resolution photochemical simulations in an urban coastal area over the Western Mediterranean. Atmos. Environ., 40, 5274-5297.
Pigeon, G., D. Legain, P. Durand, and V. Masson, 2007: Anthropogenic heat releases in an old European agglomeration (Toulouse, France). Int. J. Climatol., 27, 1969-1981.

Rotach, M. W., S.-E. Gryning, E. Batchvarova, A. Christen, and R. Vogt, 2004: Pollutant dispersion close to an urban surface-The BUBBLE Tracer Experiment. Meteor. Atmos. Phys., 87, 39-56.

Sailor, D. J., 2011: A review of methods for estimating anthropogenic heat and moisture emissions in the urban environment. Int. J. Climatol., 31, 189-199.

Soret, A., P. Jiménez, and J. M. Baldasano, 2011: Comprehensive air quality planning for the Barcelona Metropolitan Area through traffic management. Atmos. Pollut. Res., 2, 255-266.

Stewart, I. D., and T. R. Oke, 2009: Newly developed "thermal climate zones" for defining and measuring urban heat island "magnitude" in the canopy layer. Preprints, Eighth Symp. on the Urban Environment, Phoenix, AZ, Amer. Meteor. Soc., J8.2A. [Available online at http://ams.confex.com/ams/ pdfpapers/150476.pdf.]

Vesala, T., and Coauthors, 2008: Surface-atmosphere interactions over complex urban terrain in Helsinki, Finland. Tellus, 60B, 188-199.

Yaghoobian, N., J. Kleissl, and E. S. Krayenhoff, 2010: Modeling the thermal effects of artificial turf on the urban environment. J. Appl. Meteor. Climatol., 49, 332-345. 